\title{
New trends in the electrochemical sensing of dopamine
}

\author{
Krystyna Jackowska $・$ Pawel Krysinski
}

Received: 25 September 2012 /Revised: 12 November 2012 / Accepted: 13 November 2012 /Published online: 16 December 2012

(C) The Author(s) 2012 This article is published with open access at Springerlink.com

\begin{abstract}
Since the early 70s electrochemistry has been used as a powerful analytical technique for monitoring electroactive species in living organisms. In particular, after extremely rapid evolution of new micro and nanotechnology it has been established as an invaluable technique ranging from experiments in vivo to measurement of exocytosis during communication between cells under in vitro conditions. This review highlights recent advances in the development of electrochemical sensors for selective sensing of one of the most important neurotransmitters-dopamine. Dopamine is an electroactive catecholamine neurotransmitter, abundant in the mammalian central nervous system, affecting both cognitive and behavioral functions of living organisms. We have not attempted to cover a large time-span nor to be comprehensive in presenting the vast literature devoted to electrochemical dopamine sensing. Instead, we have focused on the last five years, describing recent progress as well as showing some problems and directions for future development.
\end{abstract}

Keywords Dopamine · Biosensors · Sensors ·

In vivo detection $\cdot$ Implantable sensors

\section{Introduction}

Dopamine (DA), which belongs to the catecholamine family of neurotransmitters, is crucially important in humans. It is produced in adrenal glands and several areas of the brain,

Published in the topical collection Bioelectroanalysis with guest editors Nicolas Plumeré, Magdalena Gebala, and Wolfgang

Schuhmann.

K. Jackowska $\cdot$ P. Krysinski $(\bowtie)$

Faculty of Chemistry, University of Warsaw,

02-093 Warsaw, Poland

e-mail: pakrys@chem.uw.edu.pl and is the most abundant of the catecholamines involved in brain-body integration (Fig. 1).

Dopamine is formed by decarboxylation of DOPA and is a precursor of two other neurotransmitters - adrenaline and noradrenalin (Scheme 1).

Under physiological conditions in the nervous tissues and body fluids, dopamine occurs in the form of large organic cations.

As a potent neuromodulator, it affects many aspects of brain circuitry, neuronal plasticity, and the organization and control of stress responses; it is also of crucial importance in the attention span, learning, and memory [1-4]. Dopamine also affects the cardiovascular and renal systems [5-7] and a variety of motivated behavior (e.g., perceiving rewards and pleasure). Low levels or practically complete depletion of dopamine in the central nervous system is implicated as a major cause of several neurological diseases, for example schizophrenia, Parkinson's disease, and ADHD/ADD [8-11]. In the neurotransmission process, dopamine acts as an extrasynaptic messenger molecule via volume transmission across the synaptic cleft to bind to extrasynaptic receptors ( $G$ protein-coupled receptors) and transporters [12-16] (Fig. 2). Because all drugs of abuse affect the dopaminergic pathways, much study of addiction focuses on dopamine [17].

Given the wide range of physiological and pathophysiological implications, the development of a sensor for precise and selective measurement of dopamine (and/or its metabolites) at the low levels characteristic of living system (26$40 \mathrm{nmolL}^{-1}[18,19]$ and below) can make a great contribution to disease diagnosis.

Many recently published papers have been devoted to detection of dopamine. Sampling and separation techniques for cell or tissue homogenates (microdialysis, low-flow pushpull perfusion) coupled to analytical techniques such as enzyme assays, liquid chromatography, mass spectrometry, capillary electrophoresis, with optical or electrochemical 
Fig. 1 Integrated view of brain-body interactions in response to stressful stimuli. Acute stressors change the release of different neurotransmitters in limbic areas of the brain (large rectangle), which are functionally interconnected, leading to behavioral processes for coping with the stress. The hypothalamic activation initiates the release of different body hormones and peptides, which cross the blood-brain barrier to feed back to the brain. Among these, corticosterone is important in modulating release of different neurotransmitters in the limbic areas, affecting, in turn, coping behavior (from Ref. [1], with permission)

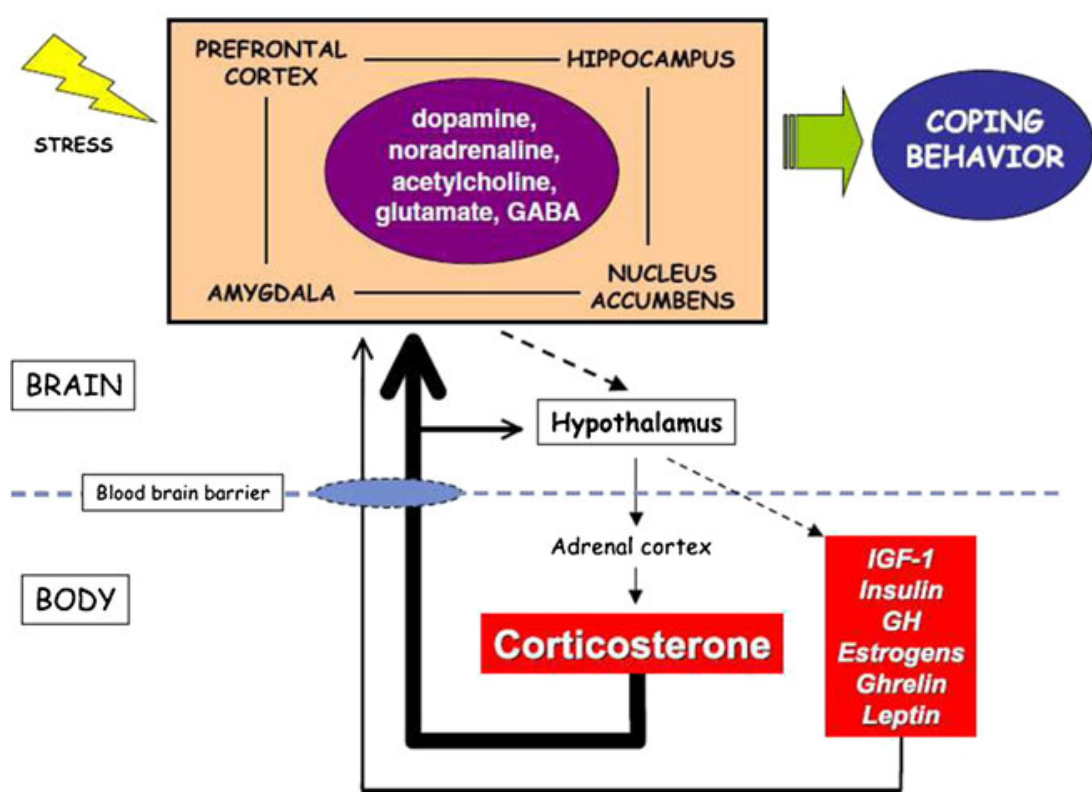

detection (e.g., biosensors) are the main techniques used for measurement of dopamine (and neurotransmitters in general). However, the most straightforward, rapid, and cost-effective is the use of electrochemical sensing techniques for detection of electroactive neurotransmitters, including dopamine.

Recent developments in electrochemical sensors focus on improvement of their sensitivity, selectivity, and biocompatibility. Miniaturization of such sensors has also been attempted, with the objective of achieving better spatial and temporal resolution, and effective multi-analyte detection. It is beyond the scope of this brief review to cover all these topics. The interested reader is referred to the paper by Kennedy [20], and references cited therein. In this paper we focus solely on amperometric sensors for dopamine.

The $2 \mathrm{e} / 2 \mathrm{H}^{+}$redox reactions of dopamine under physiological conditions constitute the basis of electrochemical detection (e.g., amperometric, differential pulse voltammetry, cyclic voltammetry) of this neurotransmitter. Currents generated in these reactions may be linearly dependent on the concentration of the electroactive molecules in the extracellular medium, enabling quantification of these compounds.<smiles>CNCC(O)c1cc(O)c(O)cc1CC(O)c1cc(O)c(C(O)CN)cc1O</smiles>

Scheme 1 Sequence of enzymatic reactions generating other catecholamines from L-DOPA
Appropriate design of a sensor system should enable numerous limitations of direct electrochemical detection of catecholamines to be overcome. Electrochemical methods have been widely used for direct measurement for dopamine, with several advantages, for example as rapid response with high accuracy and relatively easy operation. However, early work by Hubbard and coworkers revealed the effects of adsorption, orientation of adsorbed molecules, concentration, supporting electrolyte, etc., on the electrochemistry of dopamine [21, 22]. Other limitations include the relatively large oxidation potential of direct oxidative detection on the electrode and formation of phenoxy radicals with subsequent coupling and formation of passivating polymeric film on the electrode [23-25], consecutive reactions of dopaminoquinone (DOQ), a product of electrochemical DA oxidation, resulting in aminochrome formation and electrode passivation [26]. The other problem which must be solved in the electrochemical detection of dopamine is the co-existence of many interfering compounds in biological systems. Among these interfering compounds, ascorbic acid (AA), epinephrine (EP), and uric acid (UA) are particularly important because they can all be oxidized at similar potentials resulting in overlap of voltammetric responses [27-29]. It is, therefore, important to develop an electrochemical method for selective determination of dopamine with high sensitivity and a low detection limit (LOD).

In recent years, numerous attempts have been made to develop such a method. Among these, different electrode materials have been tested, including metal, carbon, and boron-doped diamond electrodes [30, 31], and different electrolytes, including ionic liquids [32]. Modified electrodes with self assembled monolayers [33, 34], covalent modification [31, 35], nanotubes, nanowires, nanoparticles [36-42], permselective membranes [43], and conducting polymer films have 
Fig. 2 Synaptic region coupling two cells, separated by a synaptic cleft $(S C)$; arrows show dopamine trafficking. $M E$, metabolic enzymes; $D R$, $D U$, neuronal dopamine release and uptake, respectively; $P R, R$, pre-synaptic and post-synaptic receptors, respectively; $V$, DA storage vesicles; $S O$, synaptic overflow

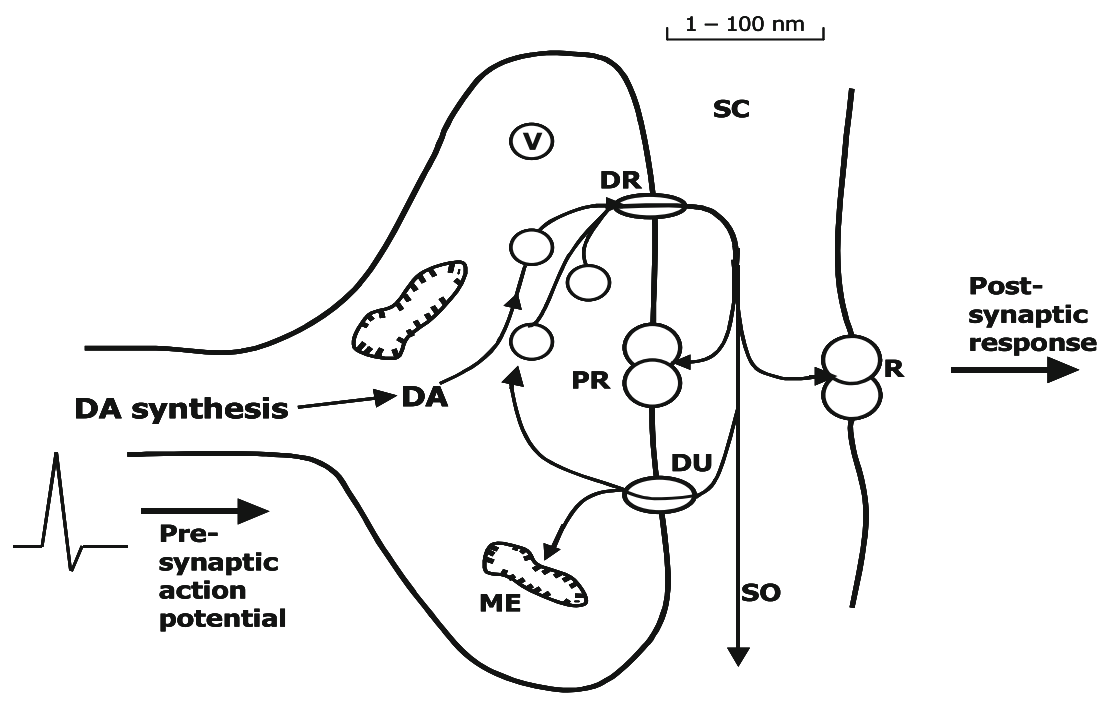

been reported to have favorable effects on detection of DA in the presence of AA, UA, or both AA and UA [38, 44-47]. Conducting polymers have several advantages in the sensor preparation for DA detection. Some of these have pendant groups (amine or carboxylic) which interact (e.g., electrostatically) with the analyte or interferent molecules, which results in better separation of the redox signals of DA, AA, and UA $[44,46,48,49]$. Another approach is to modify the electrode surface for immobilization of enzymes (e.g., tyrosinase), selective toward DA molecules [49-55].

\section{Electrochemical sensors}

Electrochemical sensors can be broadly divided in two classes-biosensors and chemical sensors. According to the IUPAC definition [56]: "the electrochemical biosensor is a self-contained integrated device, which is capable of providing specific quantitative or semi quantitative analytical information using a biological recognition element (biochemical receptor) which is retained in direct spatial contact with an electrochemical transduction element". In the literature, however, many authors use a wider definition of biosensors, focused not on the indispensability of a biological recognition element but on the type of analyte. Throughout this review, we will use the term "biosensor" according to the IUPAC convention.

In contrast with biosensors, chemical sensors contain non-biologically active elements, improving their sensitivity and selectivity in analyte detection. In electrochemical sensors, modified electrodes are widely used as sensing elements. These modified electrodes can be formed on the basis of different inorganic or organic materials characterized by good electrical conductivity and catalytic properties.

\section{Biosensors in dopamine detection}

In recent years, much effort has been devoted to improving the catalytic properties, sensitivity, and selectivity of electrochemical sensors, either by application of nanoscale materials (nanoparticles, nanowires, nanotubes) [57-62] or by use of advanced membrane materials (sol-gel composites, hydrogels, lipid membranes) for biomolecule (enzyme) immobilization [63]. Many of the electrochemical biosensors tested for dopamine detection utilize tyrosinase (Tyr), the enzyme also known as polyphenol oxidase (PPO), as recognition element. Tyrosinase is a multifunctional copper-containing oxidoreductase with two types of catalytic activity in the presence of oxygen:

1. hydroxylation of monophenols to $o$-diphenols by cresolase activity; and

2. oxidation of diphenols to $o$-quinones by catecholase activity $[64,65]$.

The resulting quinones can be further reduced electrochemically on the electrode without any mediator, reforming the original $o$-diphenol. This reaction constitutes the basis of amperometric detection at negative potentials and quantification of phenolic compounds. By the same principle, dopamine, a catechol-like phenolic compound, can be detected by amperometry with an electrode modified with tyrosinase. Application of tyrosinase to electrochemical sensing of dopamine eliminates several problems connected with consecutive reactions of DA oxidation products resulting in the formation of aminochrome [26]. Application of tyrosinase, which is sensitive to some classes of reagent only, can also reduce the problem of many interfering compounds in biological systems, for example ascorbic acid (AA), uric acid (UA), and other neurotransmitters.

The crucial issue in the development of electrochemical biosensors is immobilization of the enzyme on a conductive 
surface (electrochemical transducer). Some prerequisites should be fulfilled by the enzyme after immobilization:

- it must be efficiently immobilized on the surface, so loss of enzyme does not occur during measurement;

- it must retain its biological activity;

- it should be compatible with and chemically inert toward the host structure; and

- it should be accessible to the analyte;

There are also requirements of the matrices used for enzyme immobilization:

- the procedure for matrix formation should be simple, reproducible, and inexpensive;

- the matrix should be chemically stable in the analytical environment and inert to the enzyme and detected analytes;

- if the matrix works as a mediator in an electron-transfer process, its properties should be reversible; and

- the conductivity of the matrix should be high, especially when used in an electrochemical biosensor.

The procedures used for immobilization of enzymes on different substrates, and their advantages and disadvantages, have been widely discussed in many reviews of nanoscale materials $[57,58,62]$ and conducting polymers [66-69]. A review has been devoted to immobilization of laccase (Lac) and tyrosinase (Tyr) on different substrates [70]. Data were reported for application of biosensors to detection of phenolic compounds; there were no data on dopamine detection, however.

Methods of enzyme immobilization can be divided into two main groups - entrapment in the bulk of the matrix and entrapment on the matrix surface. Entrapment in the bulk is expected when the active layer of the biosensor is formed by mixing the enzyme with the compound used for matrix formation, e.g., carbon paste, or monomers for chemical or electrochemical polymerization of polymers. When sensor active layers are formed by the sol-gel or layer-by-layer techniques, the bulk entrapment is, again, expected to be dominant. Of course, some of the enzyme is also bonded to the matrix surface, but most is trapped within the bulk. In surface-entrapment processes, physical or chemical adsorption are used, or the enzymes are immobilized by covalent bonding to appropriately functionalized matrices. The localization and distribution of the enzyme within the matrix is crucial and can determine the characteristics and performance of the biosensor. For instance, diffusion of analyte to enzyme trapped in the bulk of the matrix is limited; physical adsorption, however, the weakness of the physical interaction and the susceptibility of the binding energy to the environment ( $\mathrm{pH}$, ionic strength, type of ions) can result in enzyme losses and instability during practical application. In comparison, covalent linking of the enzyme to the matrix seems to be the most effective means of immobilization and formation of stable biosensors. However, when surface attachment is used for biosensor formation, the main problem is insufficient enzyme (a monolayer on a surface matrix) resulting in reduced biosensor sensitivity. Another limitation is proper orientation of covalently bound enzyme; this also should be taken into account for biosensors based on the socalled direct electron transfer (DET) mechanism. It is beyond the scope of this review to discuss this type of sensor, which has already been thoroughly discussed in an excellent review by Armstrong [71].

Many efforts have been made to improve the properties of the active layer of biosensors, for example accessibility to dopamine and loading capacity, by use of conducting porous and mesoporous materials. Similarly, increased surface active site density for enzyme immobilization can be achieved by constructing the matrix with nano-scale materials, for example metal or oxide nanoparticles, carbon nanowires, nanotubes, etc. These not only increase the amount of enzyme attached to the matrix but can also catalyze the enzymatic reaction, affecting kinetic data, sensitivity, and response time of biosensors. Such an approach has also been used for formation of Tyr biosensors for dopamine detection [49-55, 72-78]. Information about different types of matrix for tyrosinase immobilization, type of entrapment, analytical data (sensitivity, detection limit, linear range), and interferences are collected in Table 1. All the experimental results presented in this table were recalculated to present them in the same units for comparison purposes.

The best characteristics for dopamine biosensors were obtained by Njagi et al. [55] and Wang et al. [78]. They achieved a single-figure nanomole level detection limit for dopamine. However, it is very difficult to compare the results, because tyrosinase activity is very rarely determined after its entrapment in the matrix (in the bulk or attached to the surface). Also the enzyme loading is generally unknown and uncontrolled. Such data are given in a few publications only $[55,76,77]$.

Response time is another important analytical property describing Tyr biosensor performance $[50,51,54,55,75$, 76]. The lowest response time $(<5 \mathrm{~s})$ for DA detection has been obtained with biosensors containing SWNT-PPy (single-wall carbon nanotubes-polypyrrole) as matrix with tyrosinase covalently bound to nanotubes functionalized with carboxyl groups [54]. The effect of matrix composition on response time was tested by Njagi et al. [55]. They obtained the lowest response times $(<8 \mathrm{~s})$ for biosensors with a relatively complex matrix consisting of Tyr-Chit/CF and $\mathrm{Tyr} / \mathrm{TiO}_{2} / \mathrm{CeO}_{2} / \mathrm{Chit} / \mathrm{CF}$, where $\mathrm{CF}$ and Chit denote carbon fiber and chitosan, respectively. Replacement of chitosan in such a matrix by a sol-gel system resulted in a three or 
Table 1 Analytical characteristics for electrochemical detection of dopamine by use of different tyrosinase biosensors

\begin{tabular}{|c|c|c|c|c|c|}
\hline Layer description (immobilization matrix) & Interferents & Linearity $\left(\mathrm{molL}^{-1}\right)$ & $\begin{array}{l}\text { Sensitivity } \\
\left(\mathrm{mAmol} \mathrm{m}^{-1} \mathrm{~L}\right)\end{array}$ & $\begin{array}{l}\text { Detection limit } \\
\left(\mathrm{molL}^{-1}\right)\end{array}$ & Ref. \\
\hline C paste, b.entrp & AA, DOPA, DOPAC & $1.5 \times 10^{-5}-2.5 \times 10^{-4}$ & 6.3 & $1.5 \times 10^{-5}$ & {$[72]$} \\
\hline Polyacrylamide gel, b.entrp & $\begin{array}{l}\text { Without AA } \\
\text { AA }\end{array}$ & $\begin{array}{l}5 \times 10^{-6}-1 \times 10^{-4} \\
3 \times 10^{-8}-1 \times 10^{-6}\end{array}$ & & $\begin{array}{l}5 \times 10^{-6} \\
3 \times 10^{-8}\end{array}$ & [73] \\
\hline Polypyrrole modified, b.entrp & AA & $5 \times 10^{-8}-8 \times 10^{-5}$ & 59 & $5 \times 10^{-8}$ & {$[74]$} \\
\hline Poly(vinyl alcohol) ferrocene-Pd-sol-gel, b.entrp & & & 0.125 & $5 \times 10^{-5}$ & [75] \\
\hline Polythiophene, b.entrp & & Up to $2 \times 10^{-4}$ & 133 & $1 \times 10^{-7}$ & {$[76]$} \\
\hline Biocomposite gel (agar, guar gum), b.entrp & & $2 \times 10^{-6}-1 \times 10^{-5}$ & & $9 \times 10^{-7}$ & [77] \\
\hline Amine-terminated BDD, surf., cov. bond. & AA & $5 \times 10^{-6}-1.2 \times 10^{-4}$ & 68.6 & & {$[50]$} \\
\hline MWNT/Nafion, b. surf. entrp & & $5 \times 10^{-6}-2.3 \times 10^{-5}$ & 12 & $5.2 \times 10^{-7}$ & {$[51]$} \\
\hline Eggshell membrane, GA, surf., phys. ads & & $5 \times 10^{-7}-2.5 \times 10^{-4}$ & & $2.5 \times 10^{-6}$ & {$[52]$} \\
\hline $\begin{array}{l}\text { Chit/GC } \\
\mathrm{TiO}_{2} / \mathrm{CeO}_{2} / \mathrm{Chit} / \mathrm{GC}, \text { b. surf. entrp }\end{array}$ & AA & & $\begin{array}{r}9.7 \\
14.9\end{array}$ & $\begin{array}{l}1.9 \times 10^{-6} \\
2.4 \times 10^{-8}\end{array}$ & [53] \\
\hline SWNT/Ppy, surf cov. bond & AA & $5 \times 10^{-6}-5 \times 10^{-5}$ & 467 & $5 \times 10^{-6}$ & {$[54]$} \\
\hline $\mathrm{Fe}_{3} \mathrm{O}_{4} /$ Chit, b. surf. entrp & AA & $2 \times 10^{-8}-7.5 \times 10^{-5}$ & 46 & $6 \times 10^{-9}$ & {$[78]$} \\
\hline $\begin{array}{l}\mathrm{TiO}_{2} / \mathrm{CeO}_{2} / \mathrm{Chit} / \mathrm{CF} \\
\mathrm{Chit} / \mathrm{CF}\end{array}$ & $\begin{array}{l}\text { AA ,UA, DOPA, DOPAC, } \\
\text { SE, EP, NorEP }\end{array}$ & $\begin{array}{l}1 \times 10^{-8}-2.2 \times 10^{-4} \\
5 \times 10^{-8}-1.2 \times 10^{-4}\end{array}$ & $\begin{array}{r}14.2 \\
7.3\end{array}$ & $\begin{array}{l}1.1 \times 10^{-9} \\
1.4 \times 10^{-7}\end{array}$ & {$[55]$} \\
\hline $\begin{array}{l}\mathrm{TiO}_{2} / \mathrm{CeO}_{2} / \text { sol-gel/CF } \\
\text { sol-gel/CF }\end{array}$ & & $\begin{array}{l}1 \times 10^{-7}-1.8 \times 10^{-4} \\
2 \times 10^{-7}-2.6 \times 10^{-4}\end{array}$ & $\begin{array}{r}33.4 \\
6.4\end{array}$ & $\begin{array}{l}4 \times 10^{-8} \\
8 \times 10^{-8}\end{array}$ & \\
\hline \multirow[t]{2}{*}{ PIn5COOH surf. cov. bond } & $\begin{array}{l}\mathrm{AA}<1 \times 10^{-4} \mathrm{molL}^{-1} \\
\mathrm{UA}<1 \times 10^{-4} \mathrm{molL}^{-1}\end{array}$ & $5 \times 10^{-7}-2 \times 10^{-5}$ & $\begin{array}{l}2,200 \\
6,200\end{array}$ & $1 \times 10^{-7}$ & [49] \\
\hline & $\mathrm{AA} / \mathrm{UA} 12.5$ & & 1,290 & & \\
\hline
\end{tabular}

b.entrp., entrapment of tyrosinase in matrix; surf. entrp., entrapment of tyrosinase on matrix surface; surf., cov. bond, entrapment of tyrosinase on surface, covalent bonding; surf., phys. ads, entrapment of tyrosinase on surface, physical adsorption; Chit, chitosan; CF, carbon fiber; PIn5COOH, poly(indolo-5-carboxylic acid); SWNT, single walled carbon nanotube; MWNT, multi walled carbon nanotube; BDD, boron-doped diamond; GC, glassy carbon; GA, glutaraldehyde; AA, ascorbic acid; UA, uric acid; DOPA, 3,4-dihydroxy-L-phenylalanine; DOPAC, dihydroxyphenylacetic acid; SE, serotonin; EP, epinephrine; NorEP, norepinephrine

fourfold increase of response time. This was ascribed to the diffusion barrier imposed by this matrix.

The important features for practical use of biosensors are:

1. sensor stability;

2. reproducibility of sensor readout, and

3. life-time.

These properties depend very much on biosensor construction and its working environment $(\mathrm{pH}$, ions, interferents, inhibitors). The reproducibility, determined in several cases $[54,55,78]$, has been found to be in the range $2.2-$ $2.5 \%$. The stability varied from a week to a few months [52, $55,75,77,78]$. The biosensors usually retained approximately $90-95 \%$ of their original response after one week under the same experimental conditions. In the long-term the stability gradually decreased to $70 \%$ or less. The best results were obtained by Pandey et al. [75]. They found their biosensor was stable over three months, retaining $95 \%$ reproducibility when stored at $4{ }^{\circ} \mathrm{C}$. However, the procedure used to evaluate stability was not described precisely. The most complex measurements of stability and reproducibility were made by Njagi et al. [55] for tyrosinase biosensors containing mixed oxides $\left(\mathrm{TiO}_{2}, \mathrm{CeO}_{2}\right)$. It was shown that the presence of oxides improved biosensor stability; this can be attributed to strong adsorption of the enzyme on the metal oxides.

For practical purposes dopamine biosensors should be tested using real biological systems, and several papers report testing of Tyr biosensors in real biological (in vivo) measurements $[55,74,77]$. In another strategy, detection of dopamine was performed in the presence of different interferents, usually ascorbic acid (AA) $[49,50,53-55,72,73]$ but also uric acid [49, 55], L-DOPA, DOPAC [55, 72], and even the presence of another catecholamines - serotonin (SE), norepinephrine (NorEP), and epinephrine (EP) [55]. It is generally accepted that Tyr biosensors can be used for selective detection of dopamine in the presence of AA, UA, and SE.

As already mentioned, in practical use all of the properties of dopamine biosensors discussed above are very important. However, to understand the mechanism of the response of the biosensor, why interferents affects its analytical performance, analytical performance, for example 
detection limit and sensitivity (assuming similar values of enzyme activity and loading) depend substantially on the type of matrix and on immobilization procedures, one should also determine physicochemical data for the enzyme, namely the values of $K_{\mathrm{M}}, V_{\max }$, and $k_{\text {cat }}$. These data are crucial for proper characterization of enzymatic reactions. $K_{\mathrm{M}}$, the so-called Michaelis-Menten constant is defined as the substrate concentration with which half of the maximum reaction rate is achieved, or half of the active enzyme sites are filled. $V_{\max }$ is the maximum rate of the enzymatic reaction (maximum turnover rate), and $k_{\text {cat }}$ reflects the turnover number of the enzyme, i.e. the number of molecules of substrate converted to product per unit time when the enzyme is working at its maximum efficiency.

A popular definition of $K_{\mathrm{M}}$ (but only valid when there is a appropriate relationship between rate constants $-k_{1}>k_{2}$ for the enzymatic reaction, where $k_{1}$ and $k_{2}$ are the reaction rate constants for complex formation and dissociation, respectively) is that it is a measure of the strength of enzymesubstrate [ES] complexes or a measure of the affinity of formation of such complexes. There are many publications on different biosensors, and on detection of different substrates (analytes); surprisingly enough, however, kinetic data for such sensors are very limited. Values of $K_{\mathrm{M}}, V_{\max }$ (or $I_{\max }$ ), with the active layer and type of Tyr entrapment in biosensors for dopamine detection are listed in Table 2. The values of $K_{\mathrm{M}}$ and $V_{\max }$ for dopamine in solution containing tyrosinase were determined spectrophotometrically. They are $2.0 \times 10^{-4} \mathrm{molL}^{-1}$ and $5.2 \times 10^{-5} \mathrm{molL}^{-1} \mathrm{~min}^{-1}$, respectively [77]. By comparing this $K_{\mathrm{M}}$ value with those obtained for immobilized tyrosinase one can conclude that entrapment of Tyr in carbon paste has not affected the catalytic step of the reaction. The higher $K_{\mathrm{M}}$ values obtained for chitosan, from eggshell membranes, results from some diffusion limitation for dopamine. The lowest value of $K_{\mathrm{M}}$ was obtained for the enzyme covalently bound to the carboxyl groups of the polymer. However, for proper characterization of biosensors we must know not only kinetic data but also the enzyme load and its activity after immobilization. Unfortunately, such complex investigations have not been conducted. There is also no specific information about the effect of interferents, for example AA and UA, on kinetic data for the enzymatic reaction.

\section{Chemical sensors in dopamine detection}

As remarked above, biosensors based on the enzyme tyrosinase have been successfully used for selective determination of dopamine in the presence of ascorbic and uric acids in a biological environment. The main problem in the practical application of such biosensors is their poor long-term stability and reproducibility. One strategy used to overcome problems with DA detection is the development chemical sensors, usually chemically modified electrodes. In the last decade many of different materials have been tested to improve catalytic affinity, to enlarge the reaction space, and to eliminate the effect of interferents. A huge amount of research has resulted in more than hundred publications in the last three years. In 2010, Compton et al. [79] reviewed the literature on amperometric detection of DA in the presence of interferents, for example AA, UA, and serotonin . They provided a brief description of modifying layers: polymers, carbon nanotubes, and other types of surface modification. In this section we focus on some new materials used for electrode modification, for example graphene [80-90], ionic liquids [91-98], and nanoparticles [99-119]. We mostly discuss articles published within the last three years. The linear range of DA detection, sensitivity, detection limit, and short descriptions of electrode composition are presented in Tables 3-6.

\section{Graphene}

Data for selective determination of DA by use of electrodes modified with graphene (GR) are listed in Table 3 [81-89]. An excellent, short review on the applications of graphene for electrochemical sensing and biosensing was recently published by Pumera et al. [80]. Graphene is a very promising material for electrochemical applications because of its very large electrical conductivity, large surface area, and relatively low cost of preparation. Electrodes can be modified with graphene suspension [81], powder [87], and graphene composites [86]. Graphene sheets [88] can also be used as electrodes. Use of reduced graphene oxide $(\mathrm{rGO})$ for DA detection has recently been studied [82-86, 88]. It is accepted that the reduced GO enhanced the electrochemical response as a result of the presence of oxygen-containing groups on the reduced GO surface [80]. In many articles the $\mathrm{rGO}$ is also called reduced graphene (rGR), but this is not correct. The DA sensors with the best detection limit (1$10 \mathrm{nmolL}^{-1}$ ) and linear range were obtained by use of electrodes modified with graphene prepared by GO reduction [82-86, 88]. It is difficult to compare the results because of lack of information about the surface properties of he graphene-modified electrodes. Some FTIR and Raman spectra can be found for graphene electrodes modified with organic compounds [82, 84, 88], and XRD and TEM have been used for their characterization [89]. There are no kinetic data for DA oxidation. The stability and reproducibility of electrodes modified with quercetin $(\mathrm{Qu}) / \mathrm{GR}[82]$ and $\mathrm{PPy} / \mathrm{GR}$ [84] have been investigated. The relative standard deviation was found to be lower than $2 \%$ [82] or $3 \%$ [84] and stability was approximately two months for Qu/GR. Graphene-based electrodes have been used to monitor DA in biological samples, for example rat striatum [82], mouse 
Table 2 Kinetic data for tyrosinase biosensors for dopamine
The abbreviations are explained in the footnote to Table 1

\begin{tabular}{llll}
\hline Layer description (immobilization) & $K_{\mathrm{M}}\left(\mathrm{molL}^{-1}\right)$ & $V_{\max }$ or $I_{\max }$ & Ref. \\
\hline C paste, b.entrp & $1.1-2.3 \times 10^{-4}$ & $0.342 \mu \mathrm{A}$ & [72] \\
Biocomposite gel (agar, guar gum), b.entrp & $5 \times 10^{-6}$ & - & {$[77]$} \\
MWNT/Nafion, b, surf. entrp & $6 \times 10^{-5}$ & - & {$[51]$} \\
Chitosan, b. surf. entrp, $\mathrm{TiO}_{2} / \mathrm{CeO}_{2} / \mathrm{Chit} / \mathrm{GC}$, & $7.99 \times 10^{-4}$ & - & {$[53]$} \\
$\quad$ b. surf. entrp & $6.7 \times 10^{-4}$ & $0.08 \mathrm{mmolL}^{-1} \mathrm{~min}^{-1}$ & {$[52]$} \\
Eggshell membrane, GA, surf, phys. ads & $1.2 \times 10^{-6}$ & $5.5 \mu \mathrm{Acm}^{-2}$ & {$[49]$} \\
PIn5COOH surf. attach, cov. bond & $1.33 \times 10^{-6}$ & $16.5 \mu \mathrm{Acm}^{-2}$ & \\
& $\left(\mathrm{AA}, \mathrm{UA}>100 \mu \mathrm{molL}^{-1}\right)$ & & \\
\hline
\end{tabular}

hippocampus tissues [83], and human serum and human urine [84, 85]. They have also been used for simultaneous determination of DA, AA, and UA [90].

Ionic liquid composite electrodes

Wai and Ivaska [96] recently reviewed the applications of ionic liquids (IL) in electrochemical sensors. The ionic liquids have unique properties - they are salts with melting points near room temperature, they have a high ionic conductivity and large electrochemical windows, and can accelerate electron transfer in several reactions. Different ionic liquids have been used to form composite IL electrodes$\mathrm{OPPF}_{6}-N$-octylpyridium hexafluorophosphate [91, 92], BMIMPF $_{6}-1$-butyl-3-methlimidazoliumhexafluorophosphate [93, 95], and $\mathrm{PMIMCH}_{3} \mathrm{COO}-1$-(3-chlorine-2hydroxypropyl)-3-methylimidazolium acetate [94]. The worst detection limit (LOD) was obtained for carbon paste containing $\mathrm{PMIMCH}_{3} \mathrm{COO}$ [94]. The low LOD of this electrode could, however, result not only from the type of IL but also from application of $\mathrm{Ni} / \mathrm{Al}$ hydroxide layers. The kinetic data for the sensor developed in this work, for example the electron-transfer rate constant, $k_{\mathrm{ct}}$, and the charge transfer coefficient, $\alpha$, were $1.66 \mathrm{~s}^{-1}$ and 0.43 , respectively. These data are somewhat lower than those obtained for functionalized ordered mesoporous carbon/ionic liquid gel/glassy carbon (f-OMC/ILgel/GC) electrodes [95], for which the detection limit was $4.1 \times 10^{-9} \mathrm{molL}^{-1}$, $k_{\mathrm{s}}=2.5 \mathrm{~s}^{-1}$, and $\alpha=0.55$. For the $\mathrm{f}-\mathrm{OMC} / \mathrm{GC}$ electrode, but without IL, these authors obtained the lower value of $k_{\mathrm{s}}=$ $0.97 \mathrm{~s}^{-1}$, indicating that the presence of IL facilitates electron transfer between dopamine and the electrode surface [95]. The stability and reproducibility of such electrodes modified with IL were also examined. The RSD was in the range $1.5-3 \%[91,92,94]$ and stability was ca 1 month for the Ni/Al-layered double hydroxide/carbon ionic liquid electrode (Ni/Al-LDH/CILE, ca $10 \%$ response decrease). The molecular sieve/carbon ionic liquid electrode (MS/ CILE) was used for monitoring DA levels in human serum [91]. Analytical data for electrodes containing ionic liquids (IL) are listed in Table 4.

\section{Metal and semiconductor nanoparticles}

Substantial growth of applications of metal and semiconductor nanoparticles for electroanalysis has recently been

Table 3 Analytical data for electrooxidation of dopamine at graphene-modified electrodes

\begin{tabular}{|c|c|c|c|c|c|c|}
\hline Electrode & Method & Interferents & $\begin{array}{l}\text { Linearity } \\
\left(\mathrm{molL}^{-1}\right)\end{array}$ & $\begin{array}{l}\text { Sensitivity } \\
\left(\mathrm{mAmol}{ }^{-1} \mathrm{~L}\right)\end{array}$ & $\begin{array}{l}\text { Detection limit } \\
\left(\mathrm{molL}^{-1}\right)\end{array}$ & Ref. \\
\hline $\mathrm{PPy} / \mathrm{GR} / \mathrm{GC}$ & $\mathrm{CV}$ & AA & $5 \times 10^{-7}-1 \times 10^{-5}$ & 94 & $1 \times 10^{-7}$ & [81] \\
\hline $\mathrm{Qu} / \mathrm{GR} / \mathrm{GC}$ & DPV & AA, UA, others & $3 \times 10^{-8}-4 \times 10^{-4}$ & - & $1 \times 10^{-8}$ & [82] \\
\hline GR/CFE & $\mathrm{CV}$ & $\mathrm{AA}, \mathrm{UA}$ & $1 \times 10^{-8}-1 \times 10^{-4}$ & - & $1 \times 10^{-8}$ & [83] \\
\hline $\mathrm{PPy} / \mathrm{rGO} / \mathrm{GC}$ & DPV & $\mathrm{AA}, \mathrm{UA}$ & $1 \times 10^{-7}-1.5 \times 10^{-4}$ & - & $2.3 \times 10^{-8}$ & [84] \\
\hline TCPP/GR/GC & DPV & AA, UA & $1 \times 10^{-7}-1 \times 10^{-6}$ & - & $2.2 \times 10^{-8}$ & [85] \\
\hline EDTA/GR/Nafion/GC silanized & DPV & $\mathrm{AA}$ & $2 \times 10^{-7}-2.5 \times 10^{-6}$ & - & $1 \times 10^{-8}$ & [86] \\
\hline $\mathrm{GR} / \mathrm{GC}$ & DPV & AA & $4 \times 10^{-6}-1 \times 10^{-4}$ & - & $2.64 \times 10^{-6}$ & [87] \\
\hline$\beta-\mathrm{CD} / \mathrm{GR} / \mathrm{GC}$ sheet & $\mathrm{CV}$ & AA & $9 \times 10^{-9}-1.3 \times 10^{-5}$ & - & $5 \times 10^{-9}$ & [88] \\
\hline GR-Chit/GC & $\mathrm{CV}$ & $\mathrm{AA}, \mathrm{UA}$ & $5 \times 10^{-6}-2 \times 10^{-4}$ & - & - & [89] \\
\hline
\end{tabular}

$\mathrm{GR}$, graphene; rGO, reduced graphene oxide; GC, glassy carbon; $\mathrm{CF}$, carbon fiber; PPy, polypyrrole; $\beta$-CD, $\beta$-cyclodextrin; Chit, chitosan; Qu, quercetin; TCPP, meso-tetra(4- $N, N, N, N$-trimethlanilinium)porphyrin 
Table 4 Analytical data for electrooxidation of dopamine on ionic liquid-modified electrodes

\begin{tabular}{lllrr}
\hline Electrode & Method & Interferents & Linearity $\left(\mathrm{mol} \mathrm{L}^{-1}\right)$ & Detection limit $\left(\mathrm{mol} \mathrm{L}^{-1}\right)$ \\
\hline MS/CILE & SWV & AA & $5 \times 10^{-8}-8 \times 10^{-4}$ & $1 \times 10^{-8}$ \\
Pglycine/CILE & SWV & AA & $1 \times 10^{-7}-3 \times 10^{-4}$ & $5 \times 10^{-9}$ \\
SCP/CILE & SWV & AA & to $1 \times 10^{-4}$ & $2.6 \times 10^{-7}$ \\
Ni/Al-LDH/CILE & CV & AA, UA, others & $1 \times 10^{-5}-1.1 \times 10^{-3}$ & $5 \times 10^{-6}$ \\
f-OMC/ILgel/GC & DPV & AA, UA & $1 \times 10^{-7}-5 \times 10^{-4}$ & {$\left[9.1 \times 10^{-9}\right]$} \\
\hline
\end{tabular}

MS, molecular sieve; CILE, carbon ionic liquid electrode; Pglycine, polyglycine; SCP, screen printing; Ni/Al-LDH, Ni/Al, layered double hydroxide; f-OMC/ILgel, functionalized ordered mesoporous carbon/ionic liquid gel

observed $[62,118,119]$. These nanoparticles perform several important functions, including an increase of the sensing surface and facilitation of electron transfer. They also facilitate electrical contact between the redox center of a biomolecule and the electrode surface. They can also be modified further. Analytical data obtained from use of electrodes modified with nanoparticles to detect DA in the presence of AA and UA are listed in Table 5. Data for simultaneous determination of DA, AA, and UA are listed in Table 6

Comparing of detection limits showed the best result for selective determination of DA in the presence of AA was obtained by use of a sensor containing conducting polymer (PEDOT) and inorganic $\mathrm{Cu}$ crystals of appropriate size [110]. It was demonstrated that optimization of the thickness of PEDOT, surface coverage of PEDOT by $\mathrm{Cu}$ nanocrystals, and their diameter, resulted in a sensor operating in the nanomolar concentration range. This high sensitivity was related to formation of a $\mathrm{Cu}(\mathrm{II})-o$-quinolate complex and its promotion of subsequent DA oxidation [110]. There is insufficient data describing the properties of the surface of electrodes modified with nano-scale materials and used for DA monitoring. Some information on surface coverage, morphology, and loading can be found for PNPy/Pd(nanoclusters) [112] and $\mathrm{Au}$ (nanoparticles)/PANI [111] composites. We were impressed by the publication describing an electrode with methylene blue adsorbed on a phosphorylated zirconia-silica (MB)SZP for which surface properties and electrode composition, for example amount of zirconia, phosphorus content, surface area, the type of surface bond, were determined [116]. Analytical data for electrodes used for simultaneous determination of DA and other analytes show the best results for simultaneous determination of DA and UA were obtained by use of an electrode modified with polypyrrole and $\mathrm{Cu}$ nanoparticles, CuNP/Ppy [113]; for detection of DA in the presence of AA,

Table 5 Analytical data for electrooxidation of dopamine on modified electrode with different nano-scale materials (selective detection of dopamine)

\begin{tabular}{|c|c|c|c|c|c|c|}
\hline Electrode & Method & Interferents & Linearity $\left(\mathrm{molL}^{-1}\right)$ & $\begin{array}{l}\text { Sensitivity } \\
\left(\mathrm{mAmol}{ }^{-1} \mathrm{~L}\right)\end{array}$ & $\begin{array}{l}\text { Detection limit } \\
\left(\mathrm{molL}^{-1}\right)\end{array}$ & Ref. \\
\hline CD-MWCNT Plu/AuNP/GC & DPV & AA, UA, other & $1 \times 10^{-6}-5 \times 10^{-5}$ & - & $1.9 \times 10^{-7}$ & [99] \\
\hline $\mathrm{Pt}-\mathrm{DEN} / \mathrm{GC}$ & FIA & UA & - & - & $19 \mathrm{ppb}$ & {$[100]$} \\
\hline AuNP & UV-visible & AA, DOPA, other & $5.4 \times 10^{-7}-5.4 \times 10^{-6}$ & - & $3.6 \times 10^{-7}$ & [101] \\
\hline $\mathrm{Au} / \mathrm{Pt} / \mathrm{Pd} / \mathrm{TiO}_{2} \mathrm{NT} / \mathrm{Ti}$ & DPV & $\mathrm{AA}, \mathrm{UA}$ & $5 \times 10^{-8}-3 \times 10^{-5}$ & - & $3 \times 10^{-8}$ & {$[102]$} \\
\hline $\mathrm{AuNP} / \mathrm{TiO}_{2} \mathrm{NT} / \mathrm{Ti}$ & $\mathrm{CV}$ & & $5 \times 10^{-4}-2.5 \times 10^{-3}$ & - & - & [103] \\
\hline $\mathrm{DHBPD} / \mathrm{TiO}_{2} \mathrm{NP} / \mathrm{CP}$ & DPV & & $8 \times 10^{-8}-2 \times 10^{-5}$ & - & $3.14 \times 10^{-8}$ & [104] \\
\hline $\mathrm{CNP} /$ f-silicate particles/ITO & DPV & AA, UA, NADH, other & $3 \times 10^{-7}-1.8 \times 10^{-5}$ & - & $3.6 \times 10^{-7}$ & [105] \\
\hline Au nanostructured & DPV & AA & $1 \times 10^{-6}-1 \times 10^{-4}$ & 139 & $5 \times 10^{-6}$ & [106] \\
\hline $\begin{array}{l}\text { a) } \mathrm{CuONP} / \mathrm{CP} \\
\text { b) } \mathrm{CuONP} / \mathrm{CP}\end{array}$ & DPV & AA & $\begin{array}{l}3 \times 10^{-7} \\
2 \times 10^{-5}\end{array}$ & $\begin{array}{l}- \\
-\end{array}$ & $\begin{array}{l}1.8 \times 10^{-7} \\
5.5 \times 10^{-8}\end{array}$ & [107] \\
\hline nanoZnO/GC & DPV & AA & $1.1 \times 10^{-7}-8 \times 10^{-4}$ & - & $6 \times 10^{-8}$ & [108] \\
\hline $\mathrm{Fe}_{2} \mathrm{O}_{3}$-SWCNT/PGE & SWV & AA & $3.2 \times 10^{-6}-3.1 \times 10^{-5}$ & - & $3.7 \times 10^{-7}$ & [109] \\
\hline $\mathrm{Cu}(\mathrm{CR})-\mathrm{PEDOT} / \mathrm{Pt}$ & DPV & AA & $\begin{array}{c}1.2 \times 10^{-8}-6.9 \times 10^{-8} \\
3 \times 10^{-7}-2 \times 10^{-6}\end{array}$ & $\begin{array}{r}9,000 \\
313\end{array}$ & $4 \times 10^{-9}$ & [110] \\
\hline
\end{tabular}

$\beta$-CD, $\beta$-cyclodextrin; MWCNT, multi-walled carbon nanotubes; SWCNT, single-walled carbon nanotubes; Plu, poly(luminal); NP, nanoparticles; NT, nanotubes; DEN, dendrimers; f, functionalized; CP, carbon paste; PGE, pyrolytic graphite electrode; DHBPD, $N, N-(2,3-$ dixydroxybenzylidine)-1,4-phenylenediamine; $\mathrm{CR}$, crystals; PEDOT, poly(3,4-ethylenedioxythiophene); a) rod-shaped $\mathrm{CuO}$ nanoparticles; b) flake-shaped CuO nanoparticles 
Table 6 Analytical data for electrooxidation of dopamine on electrodes modified with nanoscale materials (simultaneous detection)
Chit, chitosan; GR, graphene; $\mathrm{CP}$, carbon paste; CNF, carbon nanofibers; MWNT, multiwalled carbon nano tubes; IL, ionic liquid; CILE, carbon ionic liquid electrode; NP, nano particles; NC, nanoclusters; HBNBH, 2,2'-[1,7-hepthandiylbis(nitriloethylidine))-bis-hydroquinone; PANI, polyaniline; Ppy, polypyrrole; PMPy, poly ( $N$-methylpyrrole); Pfu, polyfuran; MB, methylene blue; SZP, silica/zirkonia/phosphate

\begin{tabular}{|c|c|c|c|c|c|c|}
\hline Electrode & Method & Compound & Linearity $\left(\mathrm{molL}^{-1}\right)$ & $\begin{array}{l}\text { Sensitivity } \\
\left(\mathrm{mAmol}{ }^{-1} \mathrm{~L}\right)\end{array}$ & $\begin{array}{l}\text { Detection limit } \\
\left(\mathrm{molL}^{-1}\right)\end{array}$ & Ref. \\
\hline \multirow[t]{3}{*}{ Chit/GR/GC } & \multirow[t]{3}{*}{ DPV } & DA & $1 \times 10^{-6}-2.4 \times 10^{-5}$ & & & \multirow[t]{3}{*}[90]{} \\
\hline & & UA & $2 \times 10^{-6}-4.5 \times 10^{-5}$ & & & \\
\hline & & $\mathrm{AA}$ & $5 \times 10^{-5}-1.2 \times 10^{-3}$ & & & \\
\hline \multirow[t]{2}{*}{ MWNT/IL/GC } & \multirow[t]{2}{*}{ DPV } & DA & $1 \times 10^{-7}-1.2 \times 10^{-5}$ & & $6 \times 10^{-8}$ & \multirow[t]{2}{*}{ [97] } \\
\hline & & SE & $2 \times 10^{-8}-7 \times 10^{-6}$ & & $8 \times 10^{-9}$ & \\
\hline \multirow[t]{3}{*}{ CILE/CP } & \multirow[t]{3}{*}{ DPV } & DA & $2 \times 10^{-6}-1.5 \times 10^{-3}$ & & $1 \times 10^{-6}$ & \multirow[t]{3}{*}{ [98] } \\
\hline & & UA & $2 \times 10^{-6}-2.2 \times 10^{-4}$ & & $1 \times 10^{-6}$ & \\
\hline & & $\mathrm{AA}$ & $5 \times 10^{-5}-7.4 \times 10^{-3}$ & & $2 \times 10^{-5}$ & \\
\hline \multirow[t]{2}{*}{ AuNP-PANI/GC } & \multirow[t]{2}{*}{ DPV } & DA & $7 \times 10^{-6}-1.4 \times 10^{-4}$ & & $3 \times 10^{-6}$ & \multirow[t]{2}{*}[111]{} \\
\hline & & UA & $2.9 \times 10^{-5}-7.2 \times 10^{-4}$ & & $2 \times 10^{-5}$ & \\
\hline \multirow[t]{3}{*}{$\mathrm{PdNC} / \mathrm{PMPy} / \mathrm{Pt}$} & \multirow[t]{3}{*}{ DPV } & DA & $1 \times 10^{-7}-1 \times 10^{-5}$ & 710 & $1.2 \times 10^{-8}$ & \multirow[t]{3}{*}{112} \\
\hline & & UA & $5 \times 10^{-7}-2 \times 10^{-5}$ & 280 & $2.7 \times 10^{-8}$ & \\
\hline & & $\mathrm{AA}$ & $5 \times 10^{-5}-1 \times 10^{-3}$ & 5.6 & $7 \times 10^{-6}$ & \\
\hline \multirow[t]{2}{*}{$\mathrm{CuNP} / \mathrm{PPy} / \mathrm{GC}$} & \multirow[t]{2}{*}{ DPV } & DA & $1 \times 10^{-9}-1 \times 10^{-7}$ & & $8.5 \times 10^{-10}$ & \multirow[t]{2}{*}{113} \\
\hline & & UA & $1 \times 10^{-9}-1 \times 10^{-5}$ & & $8 \times 10^{-10}$ & \\
\hline \multirow{2}{*}{$\mathrm{HBNBH} / \mathrm{TiO}_{2} \mathrm{NP} / \mathrm{CP}$} & \multirow[t]{2}{*}{ SWV } & DA & $8 \times 10^{-6}-1.4 \times 10^{-3}$ & 43.9 & $8.4 \times 10^{-7}$ & \multirow[t]{2}{*}[114]{} \\
\hline & & UA & $1 \times 10^{-4}-6 \times 10^{-4}$ & 42 & & \\
\hline \multirow[t]{3}{*}{$\mathrm{PdNC} / \mathrm{PFu} / \mathrm{Pt}$} & \multirow[t]{3}{*}{ DPV } & DA & $5 \times 10^{-7}-1 \times 10^{-4}$ & 478.4 & $4.82 \times 10^{-8}$ & \multirow[t]{3}{*}[115]{} \\
\hline & & $\mathrm{AA}$ & $5 \times 10^{-5}-1 \times 10^{-3}$ & 21.3 & $7.13 \times 10^{-6}$ & \\
\hline & & ACOP & $5 \times 10^{-7}-1 \times 10^{-4}$ & 263.7 & $7.64 \times 10^{-8}$ & \\
\hline \multirow[t]{3}{*}{$(\mathrm{MB}) \mathrm{SZP} / \mathrm{C}$} & \multirow[t]{3}{*}{ DPV } & $\mathrm{DA}$ & $6 \times 10^{-6}-1 \times 10^{-4}$ & & $1.7 \times 10^{-6}$ & \multirow[t]{3}{*}[116]{} \\
\hline & & UA & $2.2 \times 10^{-5}-3.5 \times 10^{-4}$ & & $3.7 \times 10^{-6}$ & \\
\hline & & $\mathrm{AA}$ & $1 \times 10^{-4}-1.6 \times 10^{-3}$ & & $8.3 \times 10^{-6}$ & \\
\hline \multirow[t]{3}{*}{$\mathrm{PdNP} / \mathrm{CNF} / \mathrm{C}$} & \multirow[t]{3}{*}{ DPV } & DA & $5 \times 10^{-7}-1.6 \times 10^{-4}$ & & $2 \times 10^{-7}$ & \multirow[t]{3}{*}[117]{} \\
\hline & & UA & $2 \times 10^{-6}-2 \times 10^{-4}$ & & $7 \times 10^{-7}$ & \\
\hline & & $\mathrm{AA}$ & $5 \times 10^{-5}-4 \times 10^{-3}$ & & $1.5 \times 10^{-5}$ & \\
\hline
\end{tabular}

and UA the best results were obtained by use of electrodes containing poly $(N$-methylpyrrole) and Pd clusters [112]. Interesting results were also obtained for simultaneous detection of DA, UA, and AC on a PdNP/PFu/Pt electrode [115]. It is, however, very difficult to compare results obtained with nanoparticles and clusters because the amount used is usually uncontrolled and, therefore, unknown. There are also insufficient data to enable comparison of kinetic data, for example electron-transfer rate constant for DA electrooxidation. Some data are given for nanoparticles of $\mathrm{CuO} / \mathrm{CP}$ and $\mathrm{Fe}_{2} \mathrm{O}_{3}$ SWCNT/PGE electrodes [107, 109], and it was pointed out that particle shape $(\mathrm{CuO})$ and electrode composition $\left(\mathrm{Fe}_{2} \mathrm{O}_{3}\right.$ SWCNT) affect $k_{\mathrm{s}}$ values. What can be compared for NPmodified electrodes, however, is separation of anodic peaks for the AA-DA and DA-UA pairs. The best separation results were obtained by use of $\mathrm{Pd}$ nanoparticle-modified electrodes $-\mathrm{PdNP} / \mathrm{CNF}(0.244 \mathrm{~V}, 0.148 \mathrm{~V})$ and $\mathrm{PdNC} / \mathrm{PMPy} / \mathrm{Pt}$ $(0.205 \mathrm{~V}, 0.201 \mathrm{~V})[112,117]$. The reproducibility and stability of such electrodes has also been monitored by several workers. RSD, when determined, was found to be in the range $2-5 \%$. The electrodes retained $90-92 \%$ of their initial response after storage for $7-14$ days [99, 105, 112, 113]. The electrodes were tested with real biological samples (human urine or human serum) $[102,112,113,117]$ and with pharmacological dopamine injections [99, 104, 108, 109, 114].

Taking all these data into account it is clearly apparent that the best results for selective, simultaneous determination of DA can be obtained by use of electrodes modified with conducting polymers and nanoclusters, and/or nanoparticles of selected metals $(\mathrm{Pd}, \mathrm{Cu})$. However, the properties of the surface active layer should be optimized. In our opinion, there is no need to prepare sophisticated composites or materials that are not carefully chosen and properly characterized; such an approach will not improve sensor performance and is more expensive.

Finally, comparison of biosensors with chemical sensors reveals it is possible to obtain comparable detection limits. However, the advantage of chemical sensors is the possibility of simultaneous detection of DA, AA, and UA. Most result also show that the long-term stability of chemical sensors is higher than that of biosensors. However, their stability also decreases over longer time periods, most probably as a result of adsorption of oxidation products, formed during successive measurements, on the electrode surface. Investigation of surface properties after such measurements has not been conducted. 


\section{In-vivo and in-vitro sensing-miniaturization}

Use of the sensors and biosensors described above for real time in vivo and/or in vitro monitoring of clinically relevant physiological analytes, for example dopamine and other neurotransmitters has, with few exceptions, been restricted to laboratory use. This is primarily because they suffer from poor selectivity and sensitivity when used in a biological or biomimicking environment. Other factors that restrict their application include:

1. most of the sensors developed in laboratories on the bench are too large to be used for implantation because of extensive tissue or cell damage; the same restriction applies to in-vitro extracellular measurements;

2. bio-incompatibility of materials used in their development;

3. long term stability;

4. frequent fouling compromising their sensitivity; and/or

5. concern about selectivity to the analyte of interest.

Recent developments in nano and microtechnology have enabled the manufacture of electrochemical sensors (electrodes) in the range $1-30 \mu \mathrm{m}$ in diameter. These are now available with different geometry (disc, rod, band, etc.) and materials (C, Au, Pt, Ag) $[120,121]$ and are expected to take full advantage of the results described in the previous sections of this brief review. With use of appropriate electrochemical techniques (e.g., fast scan cyclic voltammetry, FSCV), microelectrochemistry has enabled the real-time, in-vivo and/or invitro measurements with high spatial and temporal resolution of fluctuations of the neurotransmitter concentration because of its transient release and uptake by living cells. The advantages of miniaturized electrodes (whether implantable or not) for electrochemical sensing of redox neurotransmitters, for example dopamine, can be briefly summarized as follows:

1. they have improved signal-to-noise ratios, because analytical Faraday currents are substantially increased by the higher rates of mass transfer of hemispherical diffusion of the electroactive compounds;

2. their response times are much faster because of the small double-layer capacitance charging currents and time constants, resulting in the capability of high temporal resolution of neurotransmitter fluctuations; and

3. the so-called $i R$ drop is of less concern because the total analytical currents measured by such electrodes are much smaller than those measured with typical large-scale electrodes.

Nevertheless, for such a small dimensions, the major issue, relatively easily resolved for laboratory bench sensors, is the design and fabrication of the sensor-solution interface and its effect on sensitivity and selectivity toward the target dopamine and interfering agents.
Relatively few papers have addressed design of the sensorsolution interface for miniaturized implantable electrodes; most research has focused on development of the electrochemical methods. However, for clarity it is necessary to state that not all state-of-the-art electrochemical techniques, for example scanning electrochemical microscopy, SECM, can be applied to in-vivo measurements for awake, moving animals, for obvious "geometric" reasons. Until now SECM has been restricted to cell cultures or (at most) to small anaesthetized animals [122, 147]. Nevertheless, use of micro or ultramicroelectrodes (UMEs) and microfabricated electrode arrays (MEAs) is not restricted by any particular electrochemical technique and can be used both in vivo and in vitro. Here, we will summarize the state-of-the-art of electrochemical methods used for in-vivo detection of dopamine, mostly for awake, mobile animals. This will be followed by an overview of surface modification of implantable electrodes to improve biocompatibility and selectivity for dopamine, with the proviso that although such modifications can be effective at reducing interferences, they may also reduce the efficiency of the electron transfer kinetics, reducing sensor sensitivity.

\section{Electrochemical techniques for detection of dopamine with implantable electrodes}

Since the early work of Adams and colleagues [123, 124] which introduced electrochemistry to the neurosciences, numerous electrochemical techniques and electrode materials have been used to identify and resolve catecholamines. In direct electrochemical detection of in vivo and in vitro dopamine, potentiostats with a three or two-electrode configurations have been used. The two-electrode configuration, consisting of a working electrode (microelectrode or UME) and a reference electrode, is usually preferred, because the measured currents are sufficiently small to preclude polarization of the reference electrode at ca $150 \mathrm{mmolL}^{-1}$ chloride concentrations in physiological electrolytes. The reference electrode is typically a micrometer diameter silver wire coated with a silver chloride layer, positioned next to the working electrode. The techniques most commonly used for direct detection of dopamine (or other electroactive neurotransmitters) are constant-potential amperometry (DC amperometry), differential-pulse voltammetry (DPV), and fast-scan cyclic voltammetry (FSCV), the last being a so-called "dynamic" technique.

In DC amperometry, a constant potential is applied which is sufficient to oxidize dopamine (or reduce dopaquinone) and the current, related to the amount of dopamine by Faraday's law, is recorded as a function of time. With current sampling rates in the $\mathrm{kHz}$ range, this technique can resolve signals on time scales below milliseconds. This technique has been successfully used for studies of catecholamine concentrations in the brain and in brain slices [125, 126], 
exocytosis of the small synaptic vesicles [127], neuroblastoma, and other cells [128, 129]; it has the best temporal resolution because of sampling rates down to $1 \mathrm{~ms}$. However, the disadvantage of DC amperometry is that it is essentially nonselective, because all electroactive compounds that oxidize (or reduce) at the applied potential will produce a faradaic response at the electrode. Moreover, much amplification is required so the technique is susceptible to noise artifacts arising as a result of animal movement. In a variant of DC amperometry, chronoamperometry, the potential is stepped from its initial value, where no redox reaction occurs, toward a potential at which an oxidation or reduction of the analyte molecules proceeds. Then, after a given holding time, the potential is stepped back to its initial value. This variant has been applied to real-time measurement of dopamine concentrations in the cerebral fluid of the brain $[130,131]$. Yet again, it suffers from limited chemical selectivity. Nevertheless, both techniques can be successfully used to measure dopamine dynamics evoked by an electric stimulus (for example deep-brain stimulus, DBS) [132] or reward-induced firing of dopaminergic neurons [133].

Differential pulse voltammetry (DPV) is more sensitive and selective. It uses square potential pulses of constant height superimposed over a linearly increasing potential from the initial to a final value. The potential pulse of constant frequency is typically ca $25 \mathrm{mV}$. Response currents are sampled before the potential pulse and at the end of the potential pulse. The difference between these current responses is plotted against the potential of the linear ramp. Because DPV is a differential technique, the response is a current peak of amplitude proportional to analyte (dopamine) concentration and its position shows the half-wave potential (for reversible systems). By excluding the first few milliseconds of each pulse (usually lasting tens of milliseconds), the effect of the capacitative current arising as a result of charging and/or discharging of the electrical double layer at the electrode interface is typically minimized. Although differential pulse voltammetry is more sensitive than the previous techniques [133-135], it has limited time resolution, because one full scan can take longer than seconds.

Finally, perhaps the most frequently used technique for in vivo detection of neurotransmitter trafficking is fast-scan cyclic voltammetry (FSCV). This technique provides high temporal resolution without compromising very good selectivity. Since its early application by Whitman's group [136, 137], this technique has proved effective for multi-analyte detection of catecholamines with chemical selectivity [2]. In FSCV, the voltage applied to the microelectrode is rapidly cycled in a triangular fashion at a rate higher than $100 \mathrm{Vs}^{-1}$. The limits of the triangular wave are chosen so that oxidation and reduction of, e.g., dopamine, lie within this potential window and the current (both faradaic and capacitive) resulting from the process is monitored. FSCV is usually performed with bare electrodes, for which rates of electron transfer are much faster than for modified electrodes. When used with appropriate ultramicroelectrodes (UMEs), FSCV can provide high spatial resolution $[2,138]$ and time resolution. This fast scanning limits diffusion distance to the electrode and minimizes electrode fouling $[20,139,140]$. To eliminate the capacitive contribution that scales linearly with the scan rate (high-frequency cycling), careful and precise background subtraction is necessary to eliminate the signal from capacitance build-up at the electrode interface [139]. This is usually achieved by analog background subtraction, use of the Hilbert transform, or by principalcomponents analysis; it is beyond the scope of this work to analyze the advantages and drawbacks of each method. The interested reader is referred to Refs. $[20,139,140]$ and references cited therein for more detailed description.

The experimental techniques and approach used for in-vivo experiments with awake Japanese monkeys (Macaca fuscata) during cue-reward trials are summarized in Figs. 3 and 4 [133].

Lee et al. recently introduced pair-pulse voltammetry (PPV) in which a selected binary waveform with a defined time lapse is applied to an electrode which is held at a negative potential between each of two pulses [141]. This enables recording of two simultaneous, yet different, voltammograms, and enables discrimination of analytes on the basis of their adsorption behavior on the electrode [141]. More detailed information about electrochemical techniques as bioanalytical tools for invivo and in-vitro experiments can be found in several excellent recent reviews [142-148]. Here we briefly summarize the three techniques most commonly used for monitoring catecholamines in vivo by use of implanted (ultra)microelectrodes.

\section{Electrode materials, surface functionalization and coatings}

Electrode materials and the components of electrodes are selected carefully to improve sensor sensitivity, selectivity, reproducibility, robustness, and long-term stability and/or resistance to fouling in the biological environment. As already stated, a variety of noble metals have been used for microelectrode fabrication, because of the relative ease preparation and subsequent modifications, yet most research on dopamine release and uptake in vivo cited in this review relies on fiber microelectrodes fabricated from carbon, because of the apparent biocompatibility of this material. However, irrespective of electrode material, relatively few papers address the design of the sensor-solution interface for miniaturized implantable electrodes. Below we discuss some recent approaches to this problem.

Carbon and carbon-derived ultramicroelectrodes

Carbon fiber $(\mathrm{CF})$ microelectrodes are the basis of a vast amount of experimental work in neuroscience. Electrochemical characterization of dopamine oxidation on these 
Applied Waveform

FSCV

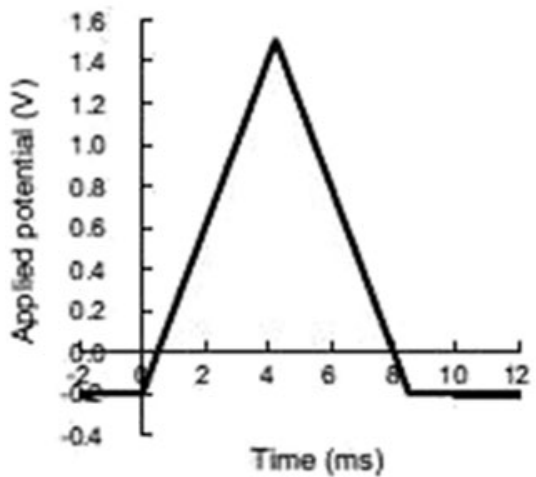

SW

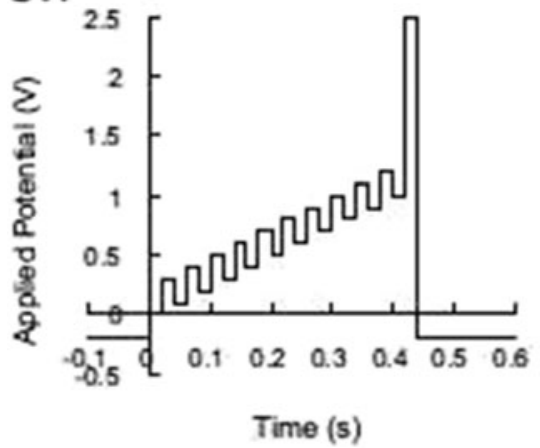

Amperometry

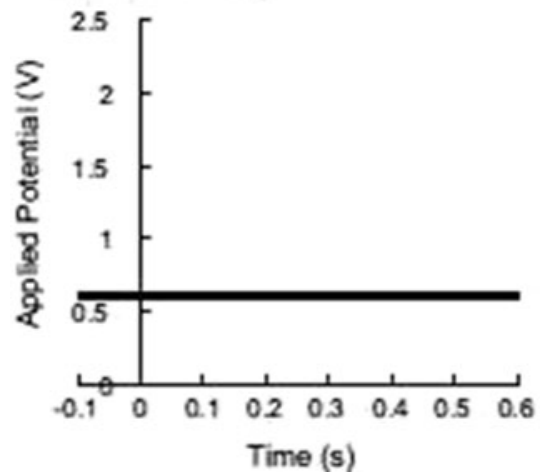

Carbon

CfFSCV -0.4 b $1.3 \mathrm{~V}$
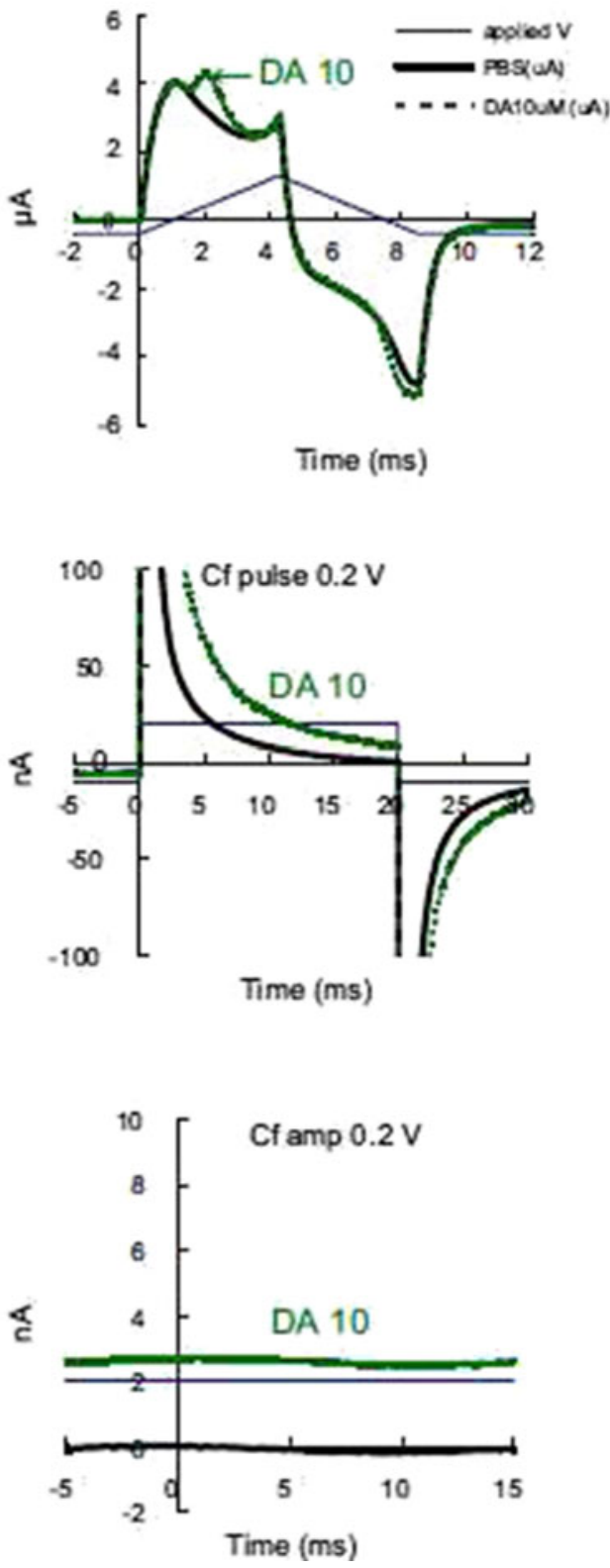

Diamond

BDD FSCV -0.2 to $1.5 \mathrm{~V}$

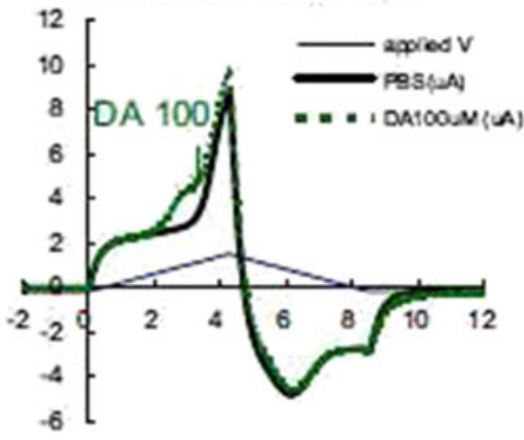

Time (ms)

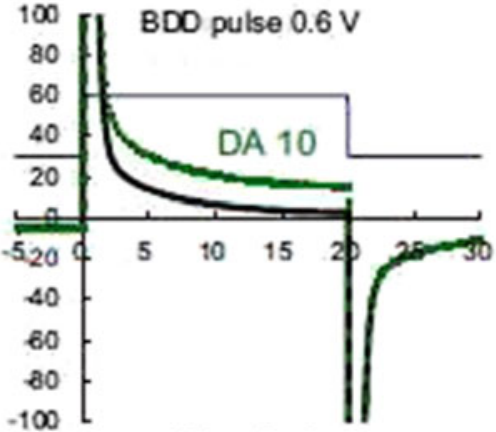

Time (ms)

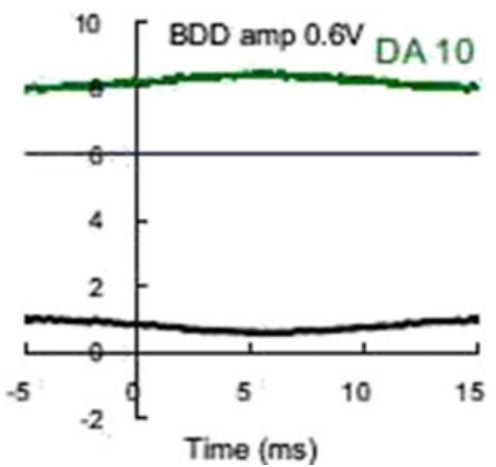

Fig. 3 Applied waveforms and current recordings for fast-scan cyclic voltammetry (FSCV; top row), square-wave differential pulse voltammetry ( $\mathrm{SW}$; middle row), and constant-potential amperometry (bottom row). The left column shows the potential applied to the $\mathrm{Ag} / \mathrm{AgCl}$ reference electrode. The middle column shows the actual current

electrodes has been well described and optimized [2, 140, 146]. These microelectrodes have been shown to be relatively unsusceptible to fouling by products of dopamine electrooxidation and much superior to other types of material for invivo electrochemical experiments [120]. It has been suggested that electrochemical detection of dopamine and other cationic neurotransmitters depends on their adsorption by the CF microelectrode. Therefore, to improve sensitivity and selectivity, measured for each waveform at the carbon fiber. For square-wave, only one pulse is indicated. The right column shows the current measured at the diamond microelectrode. Typical recorded currents in PBS (black) and in high $\left(10\right.$ and $\left.100 \mathrm{nmolL}^{-1}\right)$ concentrations of dopamine (green). (Adapted, with permission, from Ref. [133])

carbon fiber microelectrodes have undergone many treatments, for example overoxidation to develop the surface area and/or to control the surface chemistry [149-152]. Other approaches include modification of CF electrodes with carbon nanotubes, either adsorbed $[152,153]$ or self-assembled on the surface of a functionalized microelectrode [154]. Also, by use of appropriate surface polar functional groups to modify the CNTs used on CNT-modified carbon-based electrodes, the 


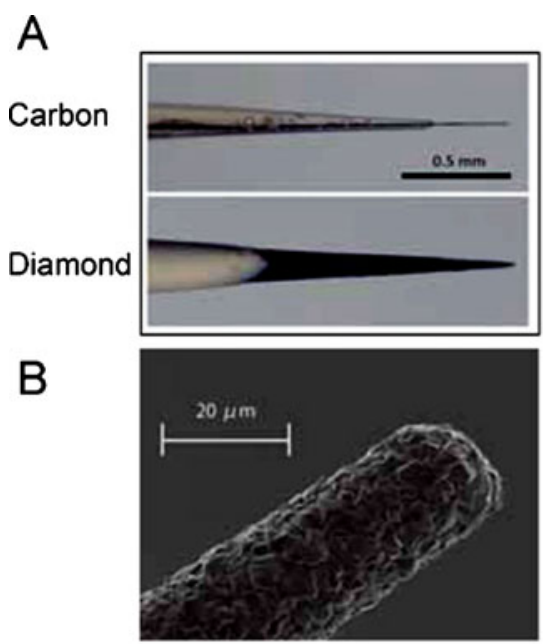

Fig. 4 Experimental methods. (a) Side view of the tips of the carbon fiber $(C f)$ and diamond microelectrode $(B D D)$. Scale bar $=500 \mu \mathrm{m}$. (b) Scanning electron microgram of the tip of the diamond microelectrode. (c) Circuit of potentiostat. (d) Electrode positions for recordings in
E

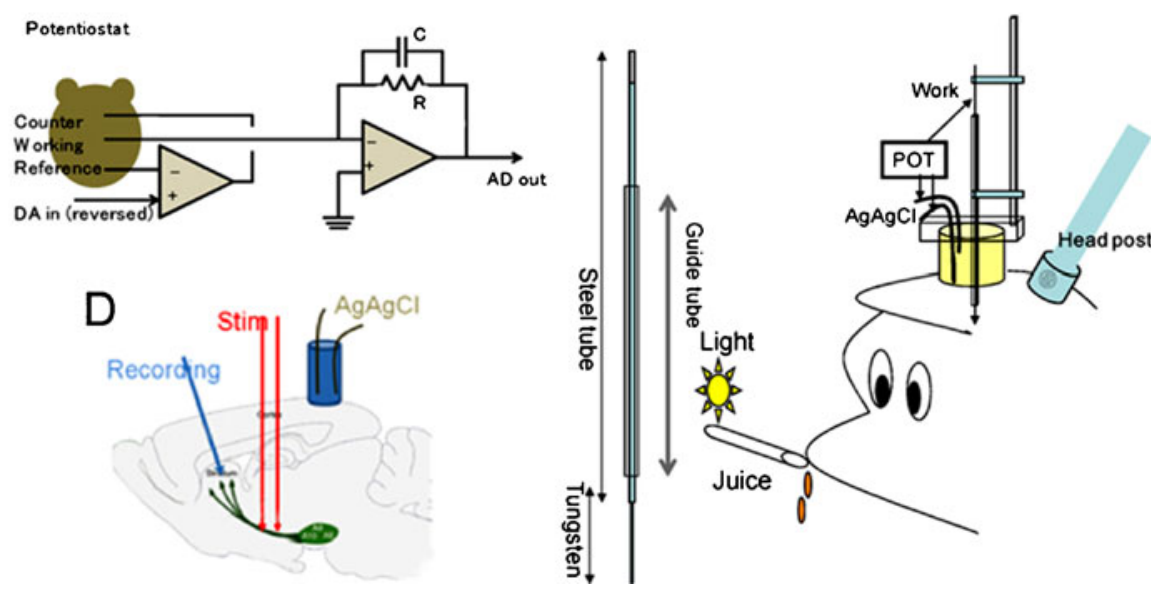

electron-transfer kinetics have been adjusted to enhance the sensitivity to cationic neurotransmitters (dopamine and serotonin). However, an unexpected result was obtained for negatively charged CNTs (carboxyl groups) - an equivalent signal increase for negatively charged ascorbic acid, a well known interferent, was also observed, suggesting that for this particular molecule, electrostatic interactions are of secondary importance [152]. A procedure for renewing the surface of a carbon microelectrode, by regenerating its electrochemically active surface while simultaneously reducing or removing fouling problems and improving electron-transfer kinetics, has recently been reported [155].

To summarize, use of carbon fiber microelectrodes seems to enable control of surface functional groups to satisfy most of the criteria for ideal implantable electrodes for dopamine detection: they are easily and reproducibly fabricated and small enough to be located in specific areas with minimal tissue damage. It has also been suggested that carbon electrodes modified with graphene perform better than multiwalled carbon nanotube-modified electrodes in selective detection of DA because of $\pi-\pi$ stacking interactions between dopamine and the graphene surface. Apparently, these interactions accelerate electron transfer for DA but hinder oxidation of ascorbic acid on the graphenemodified electrode, completely eliminating the interfering signal from ascorbic acid [89]. Another material recently considered for in-vivo electrochemical detection of dopamine is boron doped diamond (BDD). BDD is known to be a robust, durable, biocompatible electrode material with low charging (capacitive) background currents and a wide range of potential [156]. It is also highly resistant to biological fouling of its surface $[133,147]$. It has been found that extensive anodic polarization before in-vivo use improved mouse brains. (e) Left: elongated diamond microelectrode and guide cannula. Right: microelectrode positions on the monkey head. POT, potentiostat. (Adapted, with permission, from Ref. [133])

the selectivity of such electrodes for dopamine, most probably because of the formation of a carboxyl or hydroxylterminated surface. Such electrodes were found to be less sensitive to dopamine than $\mathrm{CF}$ electrodes, however.

\section{Metal electrodes}

Metal electrodes, usually $\mathrm{Pt}$ and $\mathrm{Au}$, enable both versatile surface modification and microfabrication of electrode arrays for multi-analyte monitoring and multiplexing, particularly for "lab-on-a-chip" (LOC) monitoring, differentiation, and reporting of catecholamines [121, 157-160]. Gold has the beneficial properties of adsorbing and preconcentrating catecholamines on its surface, thus increasing the sensitivity of gold electrodes to these compounds. The gold surface can, moreover, be easily modified by covalent bonding with thiol groups, enabling formation of self-assembled monolayers (SAMs) with different functionality facing the external solution [161]. Miniature gold electrodes prepared in this way have been used to characterize a variety of neurotransmitters (including dopamine) and interfering agents, and the results have been compared with analogous results obtained by use of carbon fiber microelectrodes [120].

\section{Miniaturized enzymatic electrodes; biosensors}

As already mentioned, there are relatively few reports of fabrication and use of miniaturized enzymatic biosensors for in-vivo experiments. Early reports describe ceramic-based lithographically prepared electrode arrays for electrochemical measurement of neurotransmitters [162]. These arrays were coated with glutamate oxidase crosslinked with bovine serum albumin via glutaraldehyde treatment. Their 
voltammetric performance was characterized in the presence of dopamine and hydrogen peroxide yet they were not used for in-vivo dopamine measurements. A polyphenol oxidase has also been used to prepare electrochemical microsensors for detection of dopamine and glutamate [74]. However, this enzyme was not selective for dopamine. Catalytic complexes that mimic the active site of catecholases have also been used in sensors of phenolic substrates [163-165].

Despite the innovative technology used in the nanosensing devices discussed above, as far as we are aware only one in-vivo enzymatic microbiosensor for dopamine detection has been reported [55]. This biosensor was fabricated by immobilizing tyrosinase in a matrix consisting of chitosan and ceria-based metal oxides $\left(\mathrm{CeO}_{2}\right.$ and $\left.\mathrm{TiO}_{2}\right)$ deposited on a carbon-fiber microelectrode. The chitosan coating resulted in a biocompatible sensor and, after optimization, the biosensor was reported to have an extremely large linear range, between $10 \mathrm{nmolL}^{-1}$ and $220 \mu \mathrm{molL}^{-1}$ dopamine, and sensitivity of ca $14 \mathrm{nA} \mu \mathrm{mol}^{-1} \mathrm{~L}$. Sensor selectivity against ascorbic acid (AA), uric acid (UA), serotonin, norepinephrine, epinephrine, and L-DOPA was also tested. Lack of responsive to AA and UA was attributed to the low operating potential of the sensor, and insensitivity/low sensitivity to serotonin, L-DOPA, norepinephrine, and epinephrine was attributed to the bulkier structure of these compounds, which cannot reach the active site of tyrosinase [55].

\section{Conclusions and perspectives}

In this brief review we have discussed recent achievements in the development of dopamine sensing. Many advances have been made in the construction of sensors in laboratories, on the bench, leading to a wealth of information on the production of DA electrochemical sensors with detection limits in the picomolar range, selective and specific toward DA, yet easy to operate and reusable or single-use but cost-effective. The biosensors described above are based on tyrosinase attached to different types of immobilizing and signal-transducing substrates, which enable electroanalytical detection. However, the analytical performance of some of these biosensors, for example low detection limit and low linear range of sensor response, clearly indicate that, in the presence of dominant interferents, determination of dopamine at the nanomolar levels characteristic of living system is rarely possible. The situation is very similar for the chemical sensors used for dopamine detection. Many new materials, for example carbon materials (carbon fibers, carbon nanotubes, graphene), nanoparticles, clusters $(\mathrm{Au}, \mathrm{Ag}, \mathrm{Pd}, \mathrm{Cu}$, semiconducting oxides, magnetic oxides, among others), conducting polymers, and ionic liquids, have been used for sensor construction to improve their performance. However, the desired nanomolar limit of detection has been obtained in a few cases only, when electrodes modified with conducting polymers and metal $(\mathrm{Pd}$, $\mathrm{Cu})$ nanoclusters and/or nanoparticles have been used for selective, simultaneous determination of DA in the presence of a variety of interfering agents.

Rapid progress in the use of these new materials for sensor construction has not been accompanied by appropriate characterization of the sensors. For biosensors, tyrosinase activity is very rarely determined after its entrapment in the matrix (in the bulk or attached to the surface). Enzyme loading also is usually unknown and uncontrolled. The situation is similar for chemical sensors also - surface properties and nanoparticle load are rarely controlled.

To our surprise, few kinetic data have been reported for enzymatic reactions of tyrosinase in the presence of dopamine, so it is impossible to compare kinetic data for DA electrooxidation, for example electron-transfer rate constant, or to relate these to the surface properties and analytical performance of such sensors.

To summarize, proper characterization of sensors, i.e. determination of kinetics and analytical performance, then correlation of these with material properties is more important than relentless application of increasingly sophisticated composites or new materials to sensor construction.

Currently available methodology for miniaturization could take advantage of developments in real-time mapping of neurotransmitter release zones on cell surfaces, with high spatial and temporal resolution both in vitro and in vivo, e.g., for monitoring of dopamine synaptic trafficking. Although technology, including sensor arrays, is available for combined monitoring of multiple catecholamines, design of sensor-solution interfaces for determination of the selectivity and sensitivity of sensors awaits further improvement.

Acknowledgments This work was supported by Project PSPB-079/ 2010 supported by a grant from Switzerland through the Swiss Contribution to the enlarged European Union.

Open Access This article is distributed under the terms of the Creative Commons Attribution License which permits any use, distribution, and reproduction in any medium, provided the original author(s) and the source are credited.

\section{References}

1. Mora F, Segovia G, del Arco A, de Blas M, Garrido P (2012) Stress, neurotransmitters, corticosterone and body-brain integration. Brain Res. doi:10.1016/j.brainres.2011.12.049

2. Robinson DL, Venton BJ, Heien MLAV, Wightman RM (2003) Detecting subsecond dopamine release with fast-scan cyclic voltammetry in vivo. Clin Chem 49:1763-1773

3. Hefco V, Yamada K, Hefco A, Hrticu L, Tiron A, Nabeshima T (2003) Role of the mesotelencephalic dopamine system in learning and memory processes in the rat. Eur J Pharmacol 475:55-60

4. Swamy BEK, Venton BJ (2007) Carbon nanotube-modified microelectrodes for simultaneous detection of dopamine and serotonin in vivo. Analyst 132:876-884 
5. Lupu S, Lete C, Marin M, Totir N, Balaure PC (2009) Electrochemical sensors based on platinum electrodes modified with hybrid inorganic-organic coatings for determination of 4-nitrophenol and dopamine. Electrochim Acta 54:19321938

6. Zhao Y, Gao Y, Zhan D, Liu H, Zhao Q, Kou Y, Shao Y, Li M, Zhuang Q, Zhu Z (2005) Selective detection of dopamine in the presence of ascorbic acid and uric acid by a carbon nanotubesionic liquid gel modified electrode. Talanta 66:51-57

7. Chernyshov DV, Shvedene NV, Antiova ER, Pletnev IV (2008) Ionic liquid-based miniature electrochemical sensors for the voltammetric determination of catecholamines. Anal Chim Acta 621:178-184

8. Galvan A, Wichmann T (2008) Pathophysiology of parkinsonism. Clin Neurophysiol 119:1459-1474

9. Swanson JM, Volkov ND (2009) Psychopharmacology: concepts and opinions about the use of stimulant medications. J Child Psychol Psychiatry 50:180-193

10. Kollins SH, March JS (2007) Advances in the pharmacotherapy of attention-deficit/hyperactivity disorder. Biol Psychiatry 62:951-953

11. Dalley JW, Roiser JP (2012) Dopamine, serotonin and impulsivity. Neuroscience 215:42-58

12. Smeets WJ, Gonzalez A (2000) Catecholamine systems in the brain of vertebrates: new persectives through a comparative approach. Brain Res Brain Res Rev 33:308-379

13. Miller MG (2011) The emerging role of trace amine-associated receptor 1 in the functional regulation of monoamine transporters and dopaminergic activity. J Neurochem 116:164-176

14. Neve KA, Seamans JK, Trantham-Davidson H (2004) Dopamine receptor signaling. J Recept Signal Transduct 24:165-205

15. Neve KA, Jeremy K, Seamans JK, Trantham-Davidson H (2004) Dopamine receptor signaling. J Recept Signal Transduct 24:165-205

16. Wightman RM, May LJ, Michael AC (1988) Detection of dopamine dynamics. Anal Chem 80:769A-776A

17. Sofuoglu M, Sewell RA (2009) Norepinephrine and stimulant addiction. Addict Biol 14:119-129

18. Shou M, Ferrario CR, Schultz KN, Robinson TE, Kennedy RT (2006) Monitoring dopamine in vivo by microdialysis sampling and on-line CE-laser induced fluorescence. Anal Chem 78:67176725

19. Wang D, Zhu W, An Y, Zheng J, Zhang W, Jin L, Gao H, Lin L (2008) LC with novel electrochemical detection for analysis of monoamine neurotransmitters in rat brain after administration of $(R)$-salsolinol and $(R)$-N-methylsalsolinol. Chromatographia 67:369-374

20. Perry M, Li Q, Kennedy RT (2009) Review of recent advances in analytical techniques for the determination of neurotransmitters. Anal Chim Acta 653:1-22

21. Hubbard AT, Stickney JI, Soriaga MP, Chia VKF, Rosasco SD, Schardt BS, Solomun T, Song D, White JH, Wieckowski A (1984) Electrochemical processes at well-defined surfaces. J Electroanal Chem 168:43-66

22. Salaita GN, Laguren-Davidson L, Lu F, Walton N, Wellner E, Stern DA, Batina N, Frank DG, Lin C-H, Benton CS, Hubbard AT (1988) Electrochemical reactivity of 2,2',5,5'tetrahydroxybiphenyl and related compounds adsorbed at $\mathrm{Pt}$ (111) surfaces; studies by EELS, LEED, Auger spectroscopy and cyclic voltammetry. J Electroanal Chem Interf Electrochem 245:253-273

23. Tenreiro AM, Nabais C, Correia JP, Fernandes FMSS, Romero JR, Abrantes LM (2007) Progress in the understanding of tyramine electropolymerisation mechanism. J Solid State Electrochem 11:1059-1069

24. Cooper SE, Venton BJ (2009) Fast-scan cyclic voltammetry for the detection of tyramine and octopamine. Anal Bioanal Chem 394:329-336
25. Sanchez-Cortes S, Francioso O, Garcia-Ramos JV, Ciavatta C, Gessa C (2001) Catechol polymerization in the presence of silver surface. Colloids Surf A 176:177-184

26. Majewska UE, Chmurski K, Biesaga K, Olszyna AR, Bilewicz R (2006) Dopamine oxidation at per(6-deoxy-6-thio)- $\alpha$-cyclodextrin monolayer modified gold electrodes. Electroanalysis 18:1463-1470

27. Ernst H, Knoll M (2001) Electrochemical characterisation of uric acid and ascorbic acid at a platinum electrode. Anal Chim Acta 449:129-134

28. Zhu L, Tian C, Zhai J, Yang R (2007) Sol-gel derived carbon nanotubes ceramic composite electrodes for electrochemical sensing. Sensors Actuators B Chem 125:254-261

29. Huffman ML, Venton BJ (2008) Electrochemical properties of different carbon-fiber microelectrodes using fast-scan cyclic voltammetry. Electroanalysis 20:2422-2428

30. Fujishima A, Rao TN, Popa E, Sarada BV, Yagi I, Tryk DA (1999) Electroanalysis of dopamine and NADH at conductive diamond electrodes. J Electroanal Chem 473:179-185

31. Roy PR, Saha MS, Okajima T, Park S-G, Fujishima A, Ohsaka T (2004) Selective detection of dopamine and its metabolite, DOPAC, in the presence of ascorbic acid using diamond electrode modified by the polymer film. Electroanalysis 16:1777-1784

32. Barnes EO, O'Mahony AM, Aldous L, Hardacre C, Compton RG (2010) The electrochemical oxidation of catechol and dopamine on platinum in 1-ethyl-3-methylimidazolium bis(trifluoromethylsulfonyl)imide $\left(\left[\mathrm{C}_{2} \mathrm{mim}\right]\left[\mathrm{NTf}_{2}\right]\right)$ and 1-butyl-3-methylimidazolium tetrafluoroborate $\left(\left[\mathrm{C}_{4} \mathrm{mim}\right]\left[\mathrm{BF}_{4}\right]\right)$ : adsorption effects in ionic liquid voltammetry. J Electroanal Chem 646:11-17

33. Raj CR, Okajima T, Ohsaka T (2003) Gold nanoparticle arrays for the voltammetric sensing of dopamine. J Electroanal Chem 543:127-133

34. Cabrita JF, Abrantes LM, Viana AS (2005) $N$-Hydroxysuccinimideterminated self-assembled monolayers on gold for biomolecules immobilization. Electrochim Acta 50:2117-2124

35. Zhao H, Zhang YZ, Yuan ZB (2002) Determination of dopamine in the presence of ascorbic acid using poly(hippuric acid) modified glassy carbon electrode. Electroanalysis 14:1031-1034

36. Liu A, Wei M, Honma I, Zhou H (2006) Biosensing properties of titanate nanotube films: selective detection of dopamine in the presence of ascorbate and uric acid. Adv Funct Mater 16:371-376

37. Yan W, Feng X, Chen X, Li X, Zhu J-J (2008) A selective dopamine biosensor based on $\mathrm{AgCl} @$ polyaniline core-shell nanocomposites. Bioelectrochemistry 72:21-27

38. Lange U, Roznyatouskaya NV, Mirsky VM (2008) Conducting polymers in chemical sensors and arrays. Anal Chim Acta 8:1-26

39. Zheng M, Zhou Y, Chen Y, Tang Y, Lu T (2010) Electrochemical behavior of dopamine in the presence of phosphonate and the determination of dopamine at phosphonate modified zirconia films electrode with highly antifouling capability. Electrochim Acta 55:4789-4798

40. Tyagi P, Postetter D, Saragnese DL, Randall CL, Mirski MA, Gracias DH (2009) Patternable nanowire sensors for electrochemical recording of dopamine. Anal Chem 81:9979-9984

41. Oztekin Y, Tok M, Bilici E, Mikoliunaite L, Yazicigil Z, Ramanaviciene A, Ramanavicius A (2012) Copper nanoparticle modified carbon electrode for determination of dopamine. Electrochim Acta 76:201-207

42. Ly SY (2006) Detection of dopamine in the pharmacy with a carbon nanotube paste electrode using voltammetry. Bioelectrochemistry 68:227-231

43. Jeong H, Jeon S (2008) Determination of dopamine in the presence of ascorbic acid by nafion and single-walled carbon nanotube film modified on carbon fiber microelectrode. Sensors 8:6924-6935 
44. Li NB, Ren W, Luo HQ (2008) Simultaneous voltammetric measurement of ascorbic acid and dopamine on poly(caffeic acid)-modified glassy carbon electrode. J Solid State Electrochem 12:693-699

45. Kumar SS, Mathiyarasu J, Phani KLN, Yegnaraman V (2006) Simultaneous determination of dopamine and ascorbic acid on poly (3,4-ethylenedioxythiophene) modified glassy carbon electrode. J Solid State Electrochem 10:905-913

46. Balamurugan A, Chen SM (2007) Poly(3,4-ethylenedioxythiophene-co-(5-amino-2-naphthalenesulfonic acid)) (PEDOTPANS) film modified glassy carbon electrode for selective detection of dopamine in the presence of ascorbic acid and uric acid. Anal Chim Acta 596:92-98

47. Vasantha VS, Chen SM (2006) Electrocatalysis and simultaneous detection of dopamine and ascorbic acid using poly(3,4-ethylenedioxy)thiophene film modified electrodes. J Electroanal Chem 592:77-87

48. Lin X, Zhang Y, Chen W, Wu P (2007) Electrocatalytic oxidation and determination of dopamine in the presence of ascorbic acid and uric acid at a poly ( $p$-nitrobenzenazo resorcinol) modified glassy carbon electrode. Sens Actuators B 122:309-314

49. Maciejewska J, Pisarek K, Bartosiewicz I, Krysinski P, Jackowska K, Biegunski AT (2011) Selective detection of dopamine on poly(indole-5-carboxylic acid)/tyrosinase electrode. Electrochim Acta 56:3700-3706

50. Zhou YL, Tian RH, Zhi JF (2007) Amperometric biosensor based on tyrosinase immobilized on a boron-doped diamond electrode. Biosens Bioelectron 22:822-828

51. Yu-Chen T, Chiu C-C (2007) Amperometric biosemsors based on multiwalled carbon nanotube-Nafion-tyrosinase nanobiocomposites for the determination of phenolic compounds. Sens Actuators B 125:10-16

52. Tembe S, Kubal BS, Karve M, Souza SF (2008) Glutaradelhyde activated eggshell membrane for immobilization of tyrosinase from Amorphophallus companulatus: application in construction of electrochemical biosensor for dopamine. Anal Chim Acta 612:212-217

53. Njagi J, Ispas C, Andreescu S (2008) Mixed ceria-based metal oxides biosensor for operation in oxygen restictive enviroments. Anal Chem 80:7266-7244

54. Min K, Yoo YJ (2009) Amperometric detection of dopamine based on tyrosinase-SWNTs-Ppy composite electrode. Talanta 80:1007-1011

55. Njagi J, Chernov MM, Leiter JC, Andreescu S (2010) Amperometric detection of dopamine in vivo with an enzyme based carbon fiber microbiosensor. Anal Chem 82:989-996

56. Thevenot DR, Toth K, Durst RA, Wilson GS (2001) Electrochemical biosensors: recommended definitions and classification. Biosens Bioelectron 16:121-131

57. Pumera M, Sanchez S, Ichinose I, Tang J (2007) Electrochemical nanobiosensors. Sens Actuators B 123:1195-1205

58. Yogeswaran U, Chen S-M (2008) A review on the electrochemical sensors and biosensors composed of nanowires as sensing materials. Sensors 8:290-313

59. Wang J, Lin Y (2008) Functionalized carbon nanotubes and nanofibers for biosensing applications. Trends Anal Chem 27:619-626

60. Balasubramanian K, Burghard M (2006) Biosensors based on carbon nanotubes. Anal Bioanal Chem 385:452-468

61. Lu Y, Yang M, Qu F, Shen G, Yu R (2007) Enzymefunctionalized gold nanowires for the fabrication of biosensors. Bioelectrochemistry 71:211-216

62. Pingarron JM, Yanez-Sadeno P, Gonzales-Cortes A (2008) Gold nanoparticle-based electrochemical biosensors. Electrochim Acta 53:5848-5866

63. Xu Z, Chen X, Dong S (2006) Electrochemical biosensors based on advanced bioimmobilization matrices. Trends Anal Chem 9:899-907
64. Solomon EI, Sundaram UM, Machonkin TE (1996) Multicopper oxidases and oxygenases. Chem Rev 96:2563-2605

65. Shleev SS, Tkac J, Christenson A, Ruzgas T, Yaropolov AI, Whittaker JW, Gorton L (2005) Direct electron transfer between copper-containing proteins and electrodes. Biosens Bioelectron 20:2517-2554

66. Cosnier S (1999) Biomolecule immobilization on electrode surfaces by entrapment or attachment to electrochemically polymerized films. A review. Biosens Bioelectron 14:443-456

67. Gerard M, Chaubey A, Malhorta RD (2002) Application of conducting polymers to biosensors. Biosens Bioelectron 17:345-359

68. Cosnier S (2003) Biosensors based on electropolymerized films: new trends. Anal Bioanal Chem 377:507-520

69. Ahuja T, Mir IA, Kumar D, Rajesh (2007) Biomolecular immobilization on conducting polymers for biosensing applications. Biomaterials 28:791-805

70. Duran N, Rosa MA, D'Annibale A, Gianfreda L (2002) Application of laccase and tyrosinases (phenoloxidases) immobilized on different supports: a review. Enzym Microb Technol 31:907-931

71. Cracknell JA, Vincent KA, Armstrong FA (2008) Enzymes as working or inspirational electrocatalysts for fuel cells and electrolysis. Chem Rev 108:2439-2461

72. Forzani ES, Rivas GA, Solis VM (1995) Amperometric detection of dopamine on an enzymatically modiefied carbon paste electrodes. J Electroanal Chem 382:33-40

73. Hasebe Y, Hirano T, Uchiyama S (1995) Determination of catecholamines and uric acid in biological fluids without preatreatment, using chemically amplified biosensors. Sens Actuators B 24-25:94-97

74. Cosnier S, Innocent C, Allien L, Poitry S, Tsacopoulos M (1997) An electrochemical method for making enzyme microsensors. Application of the detection to the detection of dopamine and glutamate. Anal Chem 89:968-971

75. Pandey PC, Upadhay S, Tiwari I, Singh G, Tripathi VS (2001) A novel ferrocene encapsulated palladium-linked ormosil-based electrocatalytic dopamine biosensor. Sens Actuators B 75:48-55

76. Vedrine C, Fabiano S, Tran-Minh C (2003) Amperometric tyrosinase based biosensor using an electrogenerated polythiophene film as an entrapment support. Talanta 59:535-544

77. Tembe S, Karve M, Inamdar S, Haram S, Melo J, D'Souza SF (2006) Development of electrochemical biosensor based on tyrosinase immobilized in composite biopolimeric film. Anal Biochem 349:72-77

78. Wang Y, Zhang X, Chen Y, Xu H, Tan Y, Wang S (2010) Detection of dopamine based tyrosinase- $\mathrm{Fe}_{3} \mathrm{O}_{4}$ nanoparticleschitosan nanocomposite biosensor. Am J Biomed Sci 2:209-216

79. Henstridge MC, Dickinson EJF, Aslanoglu M, Batchelor-McAuley C, Compton RG (2010) Voltammetric selectivity conferred by the modification of electrodes using conductive porous layers or films: the oxidation of dopamine on glassy carbon electrodes modified with multiwalled carbon nanotubes. Sensors Actuators B Chem 145:417-427

80. Pumera M, Ambrosi A, Bonnani A, Chng EL, Poh HL (2010) Graphene for electrochemical sensing and biosensing. Trends Anal Chem 29:954-965

81. Zhuang Z, Li J, Xu R, Xiao D (2011) Electrochemical detection of dopamine in the presence of ascorbic acid using overoxidized polypyrole/graphene modified electrode. Int J Electrochem Sci 6:2149-2161

82. Wang Z, Xia J, Zhu L, Chen X, Zhang F, Yao S, Li Y, Xia Y (2011) A selective voltammetric method for detecting dopamine at quercetin modified electrode incorporating graphene. Electroanalysis 23:2463-2471

83. Zhu M, Zeng C, Ye J (2011) Graphene-modified carbon fiber microelectrode for the detection of dopamine in mice hippocampus tissue. Electroanalysis 23:907-914 
84. Si P, Chen H, Kannan P, Kim D-H (2011) Selective and sensitive determination of dopamine by composites of polypyrrole and graphene modified electrodes. Analyst 136:5134-5138

85. Wu L, Feng L, Ren J, Qu X (2012) Electrochemical detection of dopamine using porphyrin-functionalized graphene. Biosens Bioelectron 34:57-62

86. Hon S, Kasner ML, Su S, Patel K, Cuellari R (2010) Highly sensitive and selective dopamine biosensor fabricated with silanized graphene. J Phys Chem C 114:14915-14921

87. Kim Y-R, Bong S, Kang Y-J, Yang Y, Mahajan RK, Kim JS, Kim $\mathrm{H}$ (2010) Electrochemical detection of dopamine in the presence of ascorbic acid using graphene modified electrodes. Biosens Bioelectron 25:2366-2369

88. Tan L, Zhou K-G, Zhang Y-H, Wang H-X, Wang X-D, Guo Y-F, Zhang H-L (2010) Nanomolar detection of dopamine in the presence of ascorbic acid at $\beta$-cyclodextrin/graphene nanocomposite platform. Electrochem Commun 12:557-560

89. Wang Y, Li Y, Tang L, Lu J, Li J (2009) Application of graphenemodified electrode for selective detection of dopamine. Electrochem Commun 11:889-892

90. Han D, Han T, Shan C, Ivaska A, Niu L (2010) Simultaneous determination of ascorbic acid, dopamine, uric acid with chitosangraphene modified electrode. Electroanalysis 22:2001-2008

91. Li Y, Liu X, Zeng X, Liu X, Kong B, Wei W, Luo S (2011) Selective and sensitive detection of dopamine in the presence of ascorbic acid by molecular sieve/ionic liquids composite electrode. Electrochim Acta 56:2730-2734

92. Li Y, Liu X, Wei W (2011) Square wave voltammetry for selective detection of dopamine using polyglycine modified carbon ionic liquid electrode. Electroanalysis 23:2832-2838

93. Chang J-L, Wei G-T, Zen J-M (2011) Screen -printed ionic liquid/preanodized carbon electrode: effective detection of dopamine in the presence of high concentration of ascorbic acid. Electrochem Commun 13:174-177

94. Zhu Z, Qu L, Guo Y, Zeng Y, Sun W, Huang X (2011) Electrochemical detection of dopamine on a $\mathrm{Ni} / \mathrm{Al}$ layered double hydroxide modified carbon ionic liquid electrode. Sens Actuators B 151:146-152

95. Dong J, Hu Y, Zhu S, Xu J, Xu Y (2010) A highly selective and sensitive dopamine and uric acid biosensor fabricated with functionalized ordered mesoporous carbon and hydrophobic ionic liquid. Anal Bioanal Chem 396:1755-1762

96. Wai G, Ivaska A (2008) Application of ionic liquids in electrochemical sensors. Anal Chim Acta 607:126-135

97. Sun Y, Fei J, Hou J, Qin Z, Liu Y, Hu B (2009) Simultaneous determination of dopamine and serotonin using a carbon nanotubes-ionic liquid gel modified glassy carbon electrode. Microchim Acta 165:373-379

98. Safavi A, Maleki N, Moradlou O, Tajabadi F (2006) Simultanous determination of dopamine, ascorbic acid and uric acid using carbon ionic liquids. Anal Biochem 359:224-229

99. Jia D, Dai J, Yuan H, Lei L, Xiao D (2011) Selective detection of dopamine in the presence of uric acid using a gold nanoparticles poly(luminol) hybrid film and multi-walled carbon nanotubes with incorporated $\beta$-cyclodextrin modified glassy carbon electrode. Talanta 85:2344-2351

100. Garcia MG, Armendariz GME, Godinez LA, Torres J, SepulvedaGuzman S, Bustos E (2011) Detection of dopamine in non-treated urine samples using glassy carbon electrodes modified with PAMAM dendrimer-Pt composites. Electrochim Acta 56:77127717

101. Zheng Y, Wang Y, Yang X (2011) Aptamer-based colorimetric biosensing of dopamine using unmodified nanoparticles. Sens Actuators B 156:95-99

102. Mahshid S, Li C, Mahshid SS, Askari M, Dolati A, Yang L, Luo S, Cai Q (2011) Sensitive determination of dopamine in the presence $\mathrm{TiO}_{2}$ nanotubes modiefied with $\mathrm{Pd}$, Pt and $\mathrm{Au}$ nanoparticles. Analyst 136:2322-2329

103. Hosseini M, Momeni MM, Faraji M (2010) An innovative approach to electro-oxidationof dopamine on titanium dioxide nanotubes electrode modified by gold particles. J Appl Electrochem 40:1421-1427

104. Ardakani-Mozloum M, Rajabi H, Beitollahi H, Mirjalili BBF, Akbari A, Taghavinia N (2010) Voltammetric determination of dopamine at the surface of $\mathrm{TiO}_{2}$ nanoparticles modified carbon paste electrode. Int J Electrochem Sci 5:147-157

105. Celebańska A, Tomaszewska D, Lesniewski A, Opallo M (2011) Film electrode prepared from oppositely charged silicate submicroparticles and carbon nanoparticles for selective dopamine sensing. Biosens Bioelectron 26:4417-4422

106. Plowman BJ, Mahajan M, O’Mullane AP, Bhargava SK (2010) Electrochemical detection of dopamine and cytochrome $\mathrm{c}$ at a nanostructured gold electrode. Electrochim Acta 55:8953-8959

107. Reddy S, Swamy BEK, Jayadevappa H (2012) CuO nanoparticle sensor for the electrochemical determination of dopamine. Electrochim Acta 61:78-86

108. Xia C, Ning W, Long W, Lin G (2010) Synthesis of nanochainassembled $\mathrm{ZnO}$ flowers and their application to dopamine sensing. Sens Actuators B 147:629-634

109. Adekunle AS, Agbola BO, Pillay J, Ozoemena KJ (2010) Electrocatalytical detection of dopamine at single-walled carbon nanotubes-iron(III)oxide nanoparticles platform. Sens Actuators B 148:93-102

110. Stoyanova A, Tsakova V (2010) Copper-modified poly (3,4ethylenedioxythiophene) layers for selective determination of dopamine in the presence of ascorbic acid: II role of the characteristics of the metal deposition. J Solid State Electrochem 14:1957-1965

111. Stoyanova A, Ivanov S, Tsakova V, Bund A (2011) Au nanoparticle-polyaniline nanocomposite layers obtained through layer-by-layer adsorption for the simultaneous determination of dopamine and uric acid. Electrochim Acta 56:3693-3699

112. Atta NF, El-Kady MF, Galal A (2010) Simulaneous determination of catecholamines, uric acid and ascorbic acid at physiological levels using poly(N-methylpyrrole)/Pd clusters sensor. Anal Biochem 400:78-88

113. Ulubay S, Dursun Z (2010) Cu nanoparticles incorporated polypyrrole modified GCE for sensitive simultaneous determination of dopamine and uric acid. Talanta 80:1467-1466

114. Ardakani MM, Talebi A, Nacimi H, Barzoky MN, Taghavinia N (2009) Fabrication of modified $\mathrm{TiO}_{2}$ nanoparticle carbon paste electrode for simultaneous determination of dopamine, uric acid and L-cysteine. J Solid State Electrochem 13:1433-1440

115. Atta NF, El-Kady MF, Galal A (2009) Palladium nanoclasterscoated polyfuran as a novel sensor for catecholamine neurotransmitters and paracetamol. Sens Actuators B 141:566-574

116. Arguello J, Leidens VL, Magosso HA, Ramos RR, Gushikem Y (2008) Simultaneous voltametric determination of ascorbic acid, dopamine and uric acid by methylene blue adsorbed on phosphorylated zirconia-silica composite electrode. Electrochim Acta 54:560-565

117. Huang J, Liu Y, Hou H, You T (2008) Simultaneous electrochemical determination of dopamine, uric acid and ascorbic acid using palladium nanoparticle-loaded carbon nanofibers modified electrode. Biosens Bioelectron 24:632-637

118. Katz E, Willner I, Wang J (2003) Electroanalytical and bioelectroanalytical system based on metal and semiconductor nanoparticles. Electroanalysis 16:19-44

119. Hernandez-Santos D, Gonzalez-Garcia MB, Garcia CA (2002) Metalnanoparticles based electroanalysis. Electroanalysis 14:1225-1235

120. Zachek MK, Hermans A, Wightman RM, McCarty GS (2007) Electrochemical dopamine detection: comparing gold and carbon 
fiber microelectrodes using background subtracted fast scan cyclic voltammetry. J Electroanal Chem 614:113-120

121. Zhao Y, Li S-H, Chu J, Chen Y-P, Li W-W, Yu H-Q, Liu G, Tian Y-C, Xiong Y (2012) A nano-sized Au electrode fabricated using lithographic technology for electrochemical detection of dopamine. Biosens Bioelectron 35:115-122

122. Zachek MK, Park J, Takmakov P, Wightman RM, McCarty GS (2010) Microfabricated FSCV-compatible microelectrode array for real-time monitoring of heterogeneous dopamine release. Analyst 135:1556-1563

123. Blank CL, Adams RN, Murrill E (1972) Central nervous-system effects of 6-aminodopamine and 6-hydroxydopamine. Brain Res 45:635-637

124. Adams RN, Murrill E, McCreery R, Blank L, Karolczak M (1972) 6-Hydroxydopamine, a new oxidation mechanism. Eur J Pharmacol 17:287-292

125. Troyer KP, Heien MLAV, Venton BJ, Wightman RM (2002) Neurochemistry and electroanalytical probes. Curr Opin Chem Biol 6:696-703

126. Venton BJ, Troyer KP, Wightman RM (2002) Response times of carbon microelectrodes to dynamic changes in catecholamine concentration. Anal Chem 74:539-546

127. Chen P, Xu B, Tokranova N, Feng X, Castracane J, Gillis KD (2003) Amperometric detection of quantal catecholamine secretion from individual cells on micromachined silicon chips. Anal Chem 75:518-524

128. Dong Y, Helen ML, Maxson MM, Ewing AG (2008) Amperometric measurements of catecholamine release from single vesicles in MN9D cells. J Neurochem 107:1589-1595

129. Li Z-Y, Zhou W, Wu Z-X, Zhang R-Y, Xu T (2009) Fabrication of size-controllable ultrasmall-disk electrode: monitoring single vesicle release kinetics at tiny structures with high spatio-temporal resolution. Biosens Bioelectron 24:1358-1364

130. Miller AD, Forster GL, Yeomans JS, Blaha CD (2005) Midbrain muscarinic receptors modulate morphine-induced accumbal and striatal dopamine efflux in the rat. Neuroscience 136:531-538

131. Unger EL, Eve DJ, Perez XA, Reichenbach DK, Xu YQ, Lee MK, Andrews AM (2006) Locomotor hyperactivity and alterations in dopamine neurotransmission are associated with overexpression of A53T mutant human alpha-synuclein in mice. Neurobiol Dis 21:431-443

132. Shon YM, Lee KH, Goerss SJ, Kim IY, Kimble C, Van Gompel JJ, Bennet K, Blaha CD, Chang SY (2010) High frequency stimulation of the subthalamic nucleus evokes striatal dopamine release in a large animal model of human DBS neurosurgery. Neurosci Lett 475:136-140

133. Yoshimi K, Naye $\mathrm{Y}$, Mitani N, Kato T, Inpue M, Natori S, Takahashi T, Weitemeier A, Nishikawa N, McHugh T, Einaga Y, Kitazawa S (2011) Phasic reward responses in the monkey striatum as detected by voltammetry with diamond microelectrodes. Neurosci Res 71:49-62

134. Oyama G, Yoshimi K, Natori S, Chikaoka Y, Ren Y-R, Funayama M, Shimo Y, Takahashi R, Nakazato T, Kitazawa S, Hattori N (2010) Impaired in vivo dopamine release inparkin knockout mice. Brain Res 1352:214-222

135. Suzuki A, Ivandini TA, Yoshimi K, Fujishima A, Oyama G, Nakazato T, Hattori N, Kitazawa S, Einaga Y (2007) Fabrication, characterization and application of boron-doped diamond microelectrodes for in vivo dopamine detection. Anal Chem 79:8608-8615

136. Howell JO, Kuhr WG, Ensman RF, Wightman RM (1986) Background subtraction for rapid scan voltammetry. J Electroanal Chem 209:77-90

137. Dayton MA, Ewing AG, Wightman RM (1983) Diffusional processes measured at microvoltammetric electrodes in brain tissue. J Electroanal Chem 146:189-200

138. Strand AM, Venton BJ (2008) Flame etching enhances the sensitivity of carbon-fiber microelectrodes. Anal Chem 80:3708-3715
139. Anastassiou CA, Patel BA, Arundell M, Yeoman MS, Parker KH, O'Hare D (2006) Subsecond voltammetric separation between dopamine and serotonin in the presence of ascorbate. Anal Chem 78:6990-6998

140. Keithley RB, Takmakov P, Bucher ES, Belle AM, OwessonWhite CA, Park J, Wightman RM (2011) Higher sensitivity dopamine measurements with faster-scan cyclic voltammetry. Anal Chem 83:3563-3571

141. Jang DP, Kim I, Chang SY, Min HK, Arora K, Marsh MP, Hwang SC, Kimble CJ, Bennet KE, Lee KH (2012) Paired pulse volatmmetry for differentiating complex analytes. Analyst 137:14281435

142. Lin Y, Trouillon R, Safina G, Ewing AG (2011) Chemical analysis of single cells. Anal Chem 83:4369-4392

143. Amatore C, Arbault S, Guille M, Lemaitre F (2008) Electrochemical monitoring of single cell secretion: vesicular exocytosis and oxidative stress. Chem Rev 108:2585-2621

144. Adams KL, Puchades M, Ewing AG (2008) In vitro electrochemistry of biological systems. Annu Rev Anal Chem 1:329-355

145. Wang W, Zhang S-H, Li L-M, Wang Z-L, Cheng J-K, Huang W-H (2009) Monitoring of vesicular exocytosis from single cells using micrometer and nanometer-sized electrochemical sensors. Anal Bioanal Chem 394:17-32

146. Robinson DL, Hermans A, Seipel AT, Wightman RM (2008) Monitoring rapid communication in the Brain. Chem Rev 108:2554-2584

147. Trouillon R, Svensson MI, Berglund EC, Cans A-S, Ewing AG (2012) Highlights of selected recent electrochemical measurements in living systems. Electrochim Acta. doi:10.1016/j.electacta.2012.04.164

148. Schulte A, Schuhmann W (2007) Single-cell microelectrochemistry. Angew Chem Int Ed 46:8760-8777

149. Gotch AJ, Kelly RS, Kuwana T (2003) Characterization and modeling of the nonfaradaic response of ultrahigh surface area carbon fibers by electrochemical flow injection analysis. J Phys Chem B 107:935-941

150. Duvall SH, McCreery RL (2000) Self-catalysis by catechols and quinones during heterogeneous electron transfer at carbon electrodes. J Am Chem Soc 122:6759-6764

151. Bath BD, Martin HB, Wightman RM, Anderson MR (2001) Dopamine adsorption at surface modified carbon-fiber electrodes. Langmuir 17:7032-7039

152. Jacobs CB, Vickerey TL, Venton BJ (2011) Functional groups modulate the sensitivity and electron transfer kinetics of neurochemicals at carbon nanotube modified microelectrodes. Analyst 136:3557-3565

153. Peairs MJ, Ross AE, Venton BJ (2011) Comparison of Nafionand overoxidized polypyrrole-carbon nanotubes electrodes for neurotransmitter detection. Anal Chem 3:2379-2386

154. Xiao N, Venton BJ (2012) Rapid, sensitive detection of neurotransmitters at microelectrodes modified with self assembled SWCNT forests. Anal Chem. doi:10.1021/ac301445

155. Takmakov P, Zachek MK, Keithley RB, Walsh PL, Donley C, McCarty GS, Wightman RM (2010) Carbon microelectrodes with a renewable surface. Anal Chem 82:2020-2028

156. Hutton L, Newton ME, Unwin PR, Macpherson JV (2009) Amperometric oxygen sensor based on a platinum nanoparticlemodified polycrystalline boron doped diamond disk electrode. Anal Chem 81:1023-1032

157. Johnson MD, Franklin RK, Gibson MD, Brown RB, Kipke DR (2008) Implantable microelectrode arrays for simultaneous electrophysiological and neurochemical recordings. J Neurosci Methods 174:62-70

158. Day BK, Pomerleau F, Burmeister JJ, Huettl P, Gerhardt GA (2006) J Neurochem 96:1626-1635

159. Van Gompel JJ, Chang S-Y, Goers SJ, Kim IY, Kimble C, Bennet KE, Lee KH (2010) Development of intraoperative electrochemical 
detection: wireless instantaneous neurochemical concentration sensor for deep brain stimulation feedback. Neurosurg Focus 29:E6

160. Chan F-L, Chang W-Y, Kuo L-M, Lin C-H, Wang S-W, Yang Y-S, Lu MS-C (2008) An electrochemical dopamine sensor with a CMOS detection circuit. J Micromech Microeng 18:075028

161. Tsai T-C, Guo C-X, Han H-Z, Li Y-T, Huang Y-Z, Li C-M, Chen J-J J (2012) Microelectrodes with gold nanoparticles and selfassembled monolayers for in vivo recording of striatal dopamine. Analyst 137:2813-2820

162. Burmeister JJ, Moxon K, Gerhardt GA (2000) Ceramic-based multisite microelectrodes for electrochemical recordings. Anal Chem 72:187-192
163. Fernandes SC, Osorio RE-HMB, dos Anjos A, Neves A, Micke GA, Vieira IC (2008) Determination of catechin in green tea using catechol oxidase biomimetic sensor. J Braz Chem Soc 19:1215-1223

164. Oliveita IRWZ, Osorio RE-HMB, Neves A, Vieira IC (2007) Biomimetic sensor based on a novel copper complexes for the determination of hydroquinone in cosmetics. Sens Actuators B 122:89-94

165. Fernandes SC, Vieira IC, Peralta RA, Neves A (2010) Development of a biomimetic chitosan film-coated gold electrode for determination of dopamine in the presence of ascorbic acid and uric acid. Electrochim Acta 55:7152-7157 